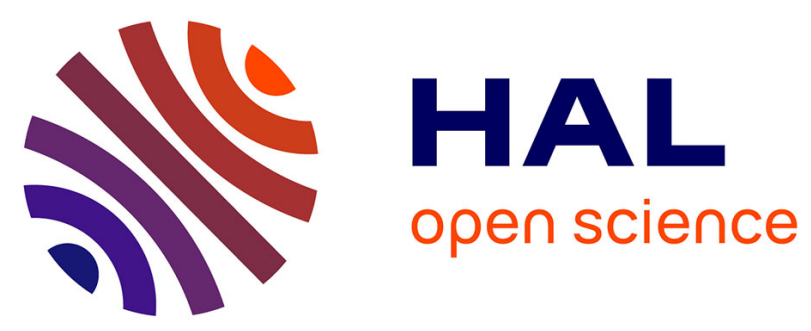

\title{
Mm-wave through-load element for on-wafer measurement applications
}

Marc Margalef-Rovira, Olivier Occello, Abdelhalim Saadi, Vanessa Avramovic, Sylvie Lepilliet, Loïc Vincent, Manuel J. Barragan, Emmanuel Pistono, Sylvain Bourdel, Christophe Gaquière, et al.

\section{To cite this version:}

Marc Margalef-Rovira, Olivier Occello, Abdelhalim Saadi, Vanessa Avramovic, Sylvie Lepilliet, et al.. Mm-wave through-load element for on-wafer measurement applications. IEEE Transactions on Circuits and Systems I: Regular Papers, 2021, 68 (8), pp.3170-3183. 10.1109/TCSI.2021.3072097 . hal-03202213

\section{HAL Id: hal-03202213 \\ https://hal.science/hal-03202213}

Submitted on 19 Apr 2021

HAL is a multi-disciplinary open access archive for the deposit and dissemination of scientific research documents, whether they are published or not. The documents may come from teaching and research institutions in France or abroad, or from public or private research centers.
L'archive ouverte pluridisciplinaire HAL, est destinée au dépôt et à la diffusion de documents scientifiques de niveau recherche, publiés ou non, émanant des établissements d'enseignement et de recherche français ou étrangers, des laboratoires publics ou privés. 


\title{
mm-Wave Through-Load Element for on-wafer Measurement Applications
}

\author{
M. Margalef-Rovira, Member, IEEE, O. Occello, A. A. Saadi, V. Avramovic, S. Lepilliet, L. Vincent, \\ M. J. Barragan, Member, IEEE, E. Pistono, S. Bourdel, Member, IEEE, C. Gaquiere, and P. Ferrari, \\ Senior Member, IEEE
}

\begin{abstract}
This paper presents an innovative ThroughLoad element aimed at characterization applications at mm-wave frequencies. The proposed structure can behave as a Through connection or as a $50-\Omega$ load depending on a DC control voltage. Among other potential applications, this system can be used to implement a transfer switch or an attenuator. A demonstrator was fabricated and measured in the STM 55-nm BiCMOS technology. Over a wide bandwidth, from $55 \mathrm{GHz}$ up to $170 \mathrm{GHz}$, experimental measurements demonstrate a maximum 1.6-dB of insertion loss when behaving as a Through connection and a minimum 14-dB of insertion loss when behaving as a $50-\Omega$ load. In both cases, the return loss is better than $10 \mathrm{~dB}$. The insertion loss at $90 \mathrm{GHz}$ is $0.6 \mathrm{~dB}$ for the Through connection and $20 \mathrm{~dB}$ for the $50-\Omega$ load connection.
\end{abstract}

Index Terms-Through-Load, on-wafer, 3-dB Coupler, Slowwave, BiCMOS, attenuator, transfer-switch millimeter-wave.

\section{INTRODUCTION}

M ODERN BiCMOS technologies enable the integration of high-performance circuits and systems operating at millimeter-wave (mm-wave) frequencies (that is, in the range 30-300 GHz) at a moderate-to-low cost. Indeed, modern SiGe BiCMOS technologies feature transistors whose $f_{T}$ or $f_{M A X}$ is beyond the mm-Wave band [1]. In this scenario, these technologies appear as a suitable candidate for high-volume production of transceivers operating in this frequency band. As a matter of fact, in the last few years, pushing circuit operation to mm-wave frequencies has been the object of an everincreasing interest from the academic and industrial communities. Among other application scenarios, the higher frequencies available in the mm-wave band allow to obtain faster data-rates and higher bandwidth in communication applications or higher spatial resolution in radar applications.

This work was supported in part by the European Union through Toward Advanced BiCMOS NanoTechnology Platforms for RF Applications, TARANTO, under the Project ECSEL JU GA 737454 and in part by the General Directorate for Enterprises (DGE), France.

M. Margalef-Rovira , V. Avramovic, S. Lepilliet, and C. Gaquiere are with Univ. Lille, CNRS, Centrale Lille, Yncrea Lille, Univ. Polytechnique Hautsde-France, UMR 8520 - IEMN, F-59000 Lille, France (e-mail : marc.margalefrovira@iemn.fr; $\quad$ vanessa.avramovic@iemn.fr; $\quad$ sylvie.lepilliet@iemn.fr; christophe.gaquiere@iemn.fr).

A. A. Saadi is with NXP France, 134 Avenue du General Eisenhower, 31100 Tolouse, France (e-mail: abdelhalim.a.saadi@gmail.com)
The faster data rate is a key parameter for enabling current and future communication standards, while radar resolution has become a key issue in the context of autonomous vehicles and advanced imaging applications.

However, pushing operation to such a high frequency range makes the characterization and test of these devices and systems a challenging task that may compromise their development. In general, a mm-wave device, as any other RF device, is characterized in terms of a number of functional performance parameters that are measured at the operation frequency (or frequency range) using dedicated high-frequency test equipment. Test setups may vary depending on the particular device under test and performance figures to extract, but they are typically based on the use of high-frequency Vector Network Analyzers (VNA). A VNA is a versatile test instrument that measures the input/output power ratios on a given Device Under Test (DUT) for determining the scattering parameters (S-Parameters) of the DUT.

However, as frequency increases, the impact of parasitics in the measurement setups may complicate significantly these characterization measurements. Thus, the effect of parasitics in calibration standards, traditionally used for VNA calibration, may lead to significantly greater measurement uncertainties [2]. Moreover, some measurements may turn impossible to perform as the losses between the measurement system and the on-wafer pads may significantly reduce the measurable range of the test instruments. For instance, load-pull measurements, devised to assess the optimum output impedance of a transistor for maximum power output [3], may require to present reflection coefficients at the output of the transistor with magnitudes close to unity. Hence, the losses in the interconnections between the external load-pull setup and the actual on-wafer DUT greatly reduce the range of impedances that are synthesized at the input of the DUT. A similar logic can be applied to power measurements, for whom the losses between the DUT and the

O. Occello, E. Pistono, S. Bourdel, and P. Ferrari are with Universite Grenoble Alpes, Grenoble INP, RFIC-Lab, 38000 Grenoble, France (e-mail: olivier.occello@univ-grenoble-alpes.fr; emmanuel.pistono@univ-grenoblealpes.fr; sylvain.bourdel@univ-grenoble-alpes.fr; philippe.ferrari@univgrenoble-alpes.fr).

M. J. Barragan is with Universite Grenoble Alpes, CNRS, Grenoble INP, TIMA, 38000 Grenoble, France (e-mail: manuel.barragan@univ-grenoblealpes.fr).

L. Vincent is with Grenoble INP, 38000 Grenoble, France (e-mail: loic.vincent@grenoble-inp.fr). 
detection system may place the output power level below the detectable threshold of the power detector.

In this context, moving the measurement system on chip may overcome some of the current limitations of mm-wave measurements. In this line, several works have reported onwafer (on-silicon) solutions for different measurement systems [4]-[6], such as power detection, load-pulling schemes or even S-Parameters measurement. Nevertheless, the proposed onwafer instruments, although being the subject of major research efforts nowadays, are far from achieving the wideband versatility and precision of external measurement instruments. For this purpose, wideband high-performance on-wafer building blocks have to be devised.

In this work, we propose an innovative element that may simplify the implementation of on-chip characterization and test instrumentation at $\mathrm{mm}$-wave frequencies. The proposed element is a two-port device that can act as: (i) a Through connection, or, (ii) a $50-\Omega$ load connected to each port, as a function of a DC control signal. As it will be presented later in this paper, this device might open the door to a full range of applications. Indeed, such a system may be very useful in the design of transfer switches or even attenuators, as discussed at the end of this paper. Hence, the aim of this work is not only to propose a Through-Load system, but also to present a wideband system performing this function. The proposed through-load element was first presented by the authors in [7] and validated using electromagnetic and transistor-level simulations. The present work presents an in-depth analysis of the principles of operation of the proposed element, details the design of a proofof-concept prototype with a central frequency of $120 \mathrm{GHz}$ and demonstrates the feasibility and performance of the ThroughLoad element with measurements results on a fabricated prototype.

The results reported hereby open the door to enhance the measurement capabilities of on-wafer instruments (for instance for the implementation of a Through-Load element in an integrated VNA), although the proposed architecture could be also used in external instruments without loss of generality. In this paper we focus our analysis on two main target applications: (i) the implementation of a transfer switch, and (ii) the implementation of an attenuator. Nevertheless, the proposed element may be useful in a wide variety of applications, especially in the fields of precise high-frequency instrumentation and Built-In Self-Test (BIST).

The rest of this paper is organized as follows: section II presents the proposed architecture and describes its working principle through a detailed analytical study. Next, section III describes the design procedure and measurement results of a demonstrator in the STM 55-nm BiCMOS technology. Section IV discusses the main applications of the proposed architecture. Finally, section V summarizes the main conclusions of this work.

\section{Proposed Through-LoAd ElEMENT}

The functionality of the proposed Through-Load Element is based on the combination of two main devices: (i) a 3-dB coupler, and (ii) two n-type Metal-Oxide-Semiconductor
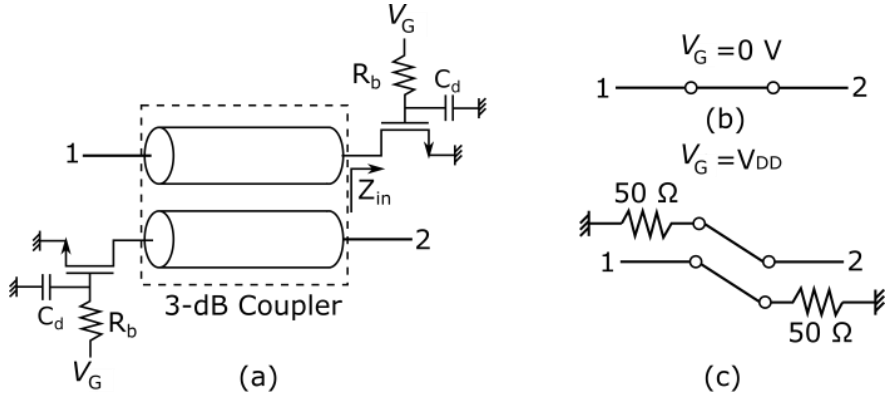

(c)

Fig. 1. (a) Schematic view of the Through-Load element. The nMOS transistors are connected to the coupled ports of the 3-dB coupler. (b) Function of the proposed device when $V_{G}=0 \mathrm{~V}$. (c) Function of the proposed device when $V_{G}=V_{D D}$.

(nMOS) transistors in a common-source configuration, as shown in Fig. 1(a). A biasing control voltage $V_{G}$ applied to the gate of the transistors allows changing the states of the Through-Load element. The system is devised in such a way that when $V_{G}$ is equal to $0 \mathrm{~V}$, the transistors are in the cutoff state and the system behaves as a through connection, as depicted in Fig. 1(b). Conversely, when the transistors are biased at $V_{G}=V_{D D}$, i.e., in their conductance region, the system behaves as a single-ended $50-\Omega$ resistance connected to ports 1 and 2, as shown in Fig. 1(c).

In the following subsections we detail how this behavior can be achieved using traditional n-type MOS Field-Effect Transistors (MOSFET) and 3-dB couplers. Moreover, we develop analytical design guidelines that take into account the effect of the coupler and transistors main non-idealities on the performance of the Through-Load element.

\section{A. Through-Load Element operation principle}

In this section the working principle of the proposed architecture is described. As introduced previously, the aim is to propose a wideband system. Hence, a frequency-dependent analysis must be carried out.

Let us consider an ideal 3-dB coupler integrated using the coupled-line architecture and loaded at its coupled outputs (i.e., ports II and III) by an impedance $Z_{\text {load }}$, as shown in Fig. 2. The choice of this architecture will be subsequently justified later in this section. Let us begin by considering the S-Parameter matrix of the coupler. When matched at the reference impedance, $Z_{0}$, we can write,

$$
\left[\begin{array}{l}
b_{1} \\
b_{2} \\
b_{3} \\
b_{4}
\end{array}\right]=\left[\begin{array}{cccc}
0 & S_{I I, I} & S_{I I I, I} & 0 \\
S_{I I, I} & 0 & 0 & S_{I I I, I} \\
S_{I I I, I} & 0 & 0 & S_{I I, I} \\
0 & S_{I I I, I} & S_{I I, I} & 0
\end{array}\right] \cdot\left[\begin{array}{l}
a_{1} \\
a_{2} \\
a_{3} \\
a_{4}
\end{array}\right] .
$$

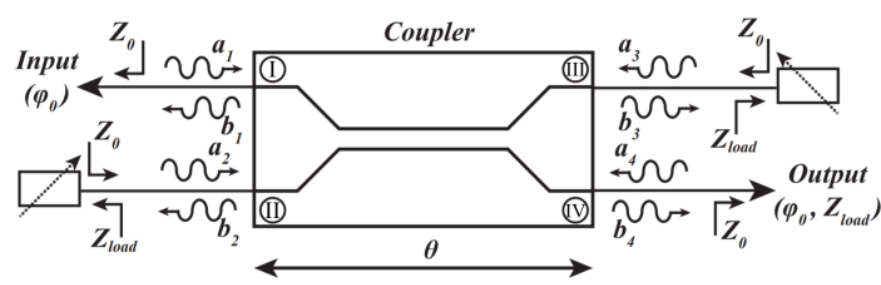

Fig. 2. Ideal 3-dB coupler loaded by $Z_{\text {load }}$ impedances. 
Where $a_{i}$ and $b_{i}$ represent the incident and reflected power waves at the coupler ports, as represented in Fig. 2, and $S_{i j}$ represent the S-Parameters of the coupler. In the case of a perfectly matched coupler, $a_{4}$ presents a null value. Hence,

$$
\left\{\begin{array}{l}
b_{1}=S_{I I, I} \cdot a_{2}+S_{I I I, I} \cdot a_{3} \\
b_{2}=S_{I I, I} \cdot a_{1} \\
b_{3}=S_{I I I, I} \cdot a_{1} \\
b_{4}=S_{I I I, I} \cdot a_{2}+S_{I I, I} \cdot a_{3}
\end{array}\right.
$$

Now, let us consider the reflection coefficient at the interface between the loads and the coupler (i.e., ports II and III). This reflection coefficient $\Gamma_{L}$ can be written as,

$$
\Gamma_{L}=\frac{Z_{\text {load }}-Z_{0}}{Z_{\text {load }}+Z_{0}} .
$$

Hence,

$$
a_{2}=\Gamma_{L} \cdot b_{2}
$$

and,

$$
a_{3}=\Gamma_{L} \cdot b_{3}
$$

Then, $a_{2}$ and $a_{3}$ in (2) can be substituted by (4) and (5), leading to:

$$
\left\{\begin{array}{l}
b_{1}=S_{I I, I} \cdot \Gamma_{L} \cdot b_{2}+S_{I I I, I} \cdot \Gamma_{L} \cdot b_{3} \\
b_{2}=S_{I I, I} \cdot a_{1} \\
b_{3}=S_{I I I, I} \cdot a_{1} \\
b_{4}=S_{I I I, I} \cdot \Gamma_{L} \cdot b_{2}+S_{I I, I} \cdot \Gamma_{L} \cdot b_{3}
\end{array}\right.
$$

Substituting the expressions of $b_{2}$ and $b_{3}$ in (6) into the expressions of $b_{1}$ and $b_{4}$ in (6) yields,

$$
b_{1}=\Gamma_{L}\left(S_{I I, I}^{2}+S_{I I I, I}^{2}\right) a_{1}
$$

and

$$
b_{4}=2 \Gamma_{L} \cdot S_{I I, I} \cdot S_{I I I, I} \cdot a_{1},
$$

Hence, $S_{11}$, which represents the $S_{I, I}$ of a coupler loaded by $Z_{\text {load }}$, can be expressed as,

$$
S_{11}=\frac{b_{1}}{a_{1}}=\Gamma_{L}\left(S_{I I, I}^{2}+S_{I I I, I}^{2}\right),
$$

and $S_{21}$, which represents the $S_{I V, I}$ of a coupler loaded by $Z_{\text {load }}$, as,

$$
S_{21}=\frac{b_{4}}{a_{1}}=2 \Gamma_{L} \cdot S_{I I, I} \cdot S_{I I I, I} .
$$

It can be demonstrated [8] that $S_{I I, I}$ in a lossless, perfectlymatched coupler can be expressed as,

$$
S_{I I, I}=\frac{j k \sin \theta}{\sqrt{1-k^{2}} \cos \theta+j \sin \theta} .
$$

where $\theta$ represents the electrical length of the coupler and $k$ the coupling coefficient. On the other hand, the expression of $S_{I I I, I}$, in a coupler under these considerations, can be demonstrated to be:

$$
S_{I I I, I}=\frac{\sqrt{1-k^{2}}}{\sqrt{1-k^{2}} \cos \theta+j \sin \theta} .
$$

As the coupler is considered to present a 3-dB coupling, then $k=1 / \sqrt{2}$.

Under these considerations, at the frequency for which the coupler presents $\theta=\pi / 2$ radians (i.e., the central frequency of the coupler) $S_{11}$ is null and $S_{21}=-j \cdot \Gamma_{L}$. Note that this behavior, when $\theta=\pi / 2$, would also hold for a branchline coupler.

Next, let us analyze the expressions in (9) and (10), as a function of $\theta$ and $\left|\Gamma_{L}\right|$. Note that the analysis over different values of $\theta$ is equivalent to a frequency analysis. Thus, Fig. 3 shows the $S_{11}$ magnitude for different coupler electrical lengths (X-axis) and different load reflection coefficients (Y-axis). It can be observed that such a structure is matched to $Z_{0}$ over a wide range of frequencies for any value of $\Gamma_{L}$. In addition, an ideal 3-dB coupler under this configuration would be matched to $Z_{0}$ when $\Gamma_{L}=0$ (i.e., $Z_{\text {load }}=Z_{0}$ ) at any frequency, which is obviously an expected result.

On the other hand, Fig. 4 displays the magnitude of $S_{21}$ as a function of coupler electrical lengths (X-axis) and different load reflection coefficients (Y-axis). Similar conclusions can be derived. Firstly, the proposed system shows similar performance over a wide band. In addition, when $\left|\Gamma_{L}\right|=0$, the system shows an infinite insertion loss (i.e., $\left|S_{21}\right|=0$ ), which is also an expected result since the coupled-line coupler type is backward.

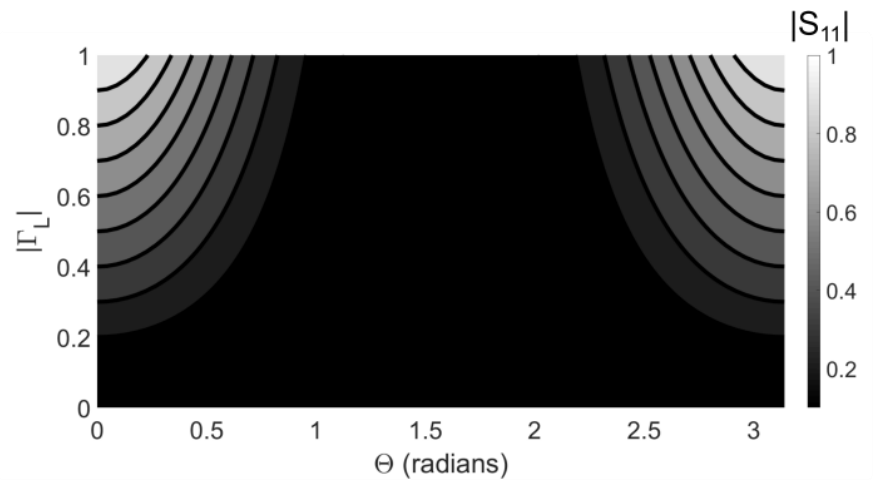

Fig. 3. $\left|S_{11}\right|$ of an ideal 3-dB coupler loaded by $Z_{\text {load }}$ impedances as a function of $\theta$ and $\left|\Gamma_{L}\right|$. 


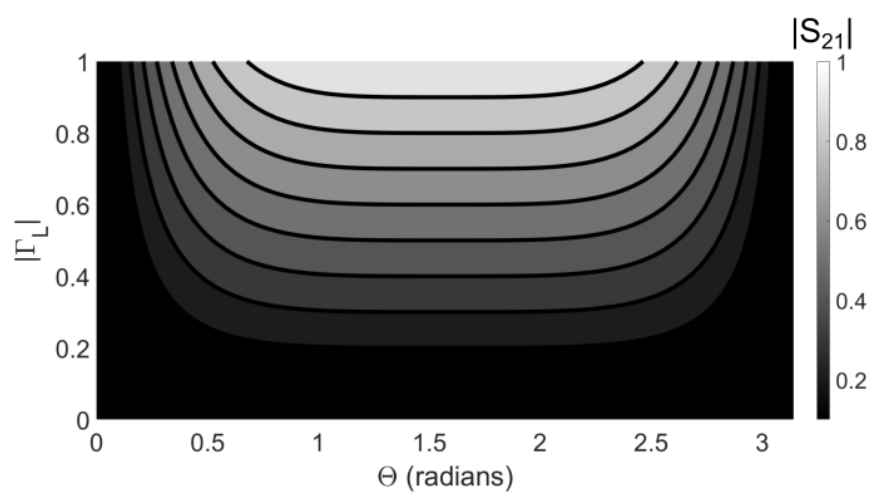

Fig. 4. $\left|S_{21}\right|$ of an ideal 3-dB coupler loaded by $Z_{\text {load }}$ impedances as a function of $\theta$ and $\left|\Gamma_{L}\right|$.

Using these results, it can be concluded that if we consider a load presenting two programmable states with a unitary and a null reflection coefficient $\left|\Gamma_{L}\right|$, the system behaves as a Through connection over a wide band of frequencies when $\left|\Gamma_{L}\right|=1$ and as a $Z_{0}$ load, at both ports of the system, when $\left|\Gamma_{L}\right|=0$ for any frequency.

If $Z_{0}$ is considered to be purely real, $\left|\Gamma_{\mathrm{L}}\right|$ presents a null magnitude for $Z_{L}=Z_{0}$. On the other hand $\left|\Gamma_{L}\right|=1$ when

$$
\left\{\begin{array}{l}
\mathfrak{R}\left(Z_{\text {load }}\right)=0 \\
\mathfrak{R}\left(Z_{\text {load }}\right)=\infty
\end{array} \quad \forall \Im\left(Z_{\text {load }}\right)\right.
$$

Summarizing, the dual behavior of the system (i.e., Through and Load) can be achieved with a load presenting either a real part of its impedance equal to zero or to infinity for obtaining the Through state and a $Z_{L}=Z_{0}$ for the Load state.

For the sake of simplicity, $Z_{0}$ is considered to be $50 \Omega$ for the rest of this paper, as it is the reference impedance in most systems.

\section{B. 3-dB Coupler}

Generally speaking, there are two widely employed design styles for the implementation of mm-Wave integrated 3-dB couplers: (i) the branchline coupler [9], and (ii) the coupled-line coupler [8], shown in Fig. 5(a) and Fig. 5(b), respectively.

The branchline couplers can be integrated in a conventional integrated technology with relative ease. However, they show reduced bandwidth performance, as compared to their coupledlines counterparts. To illustrate this issue, let us consider two ideal 50- $\Omega$ 3-dB couplers, with central frequencies of $100 \mathrm{GHz}$, one designed using a branchline coupler architecture and

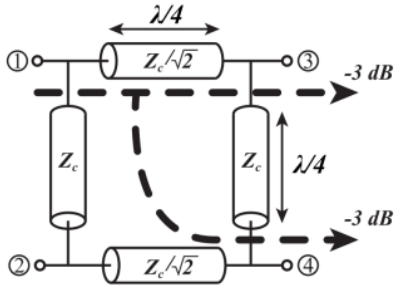

(a)

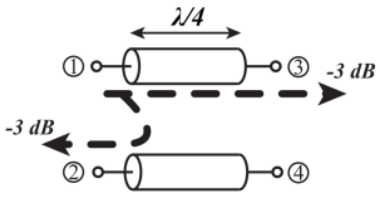

(b)
Fig. 5. Schematic view of (a) a branchline coupler and, (b) a coupled-line coupler.

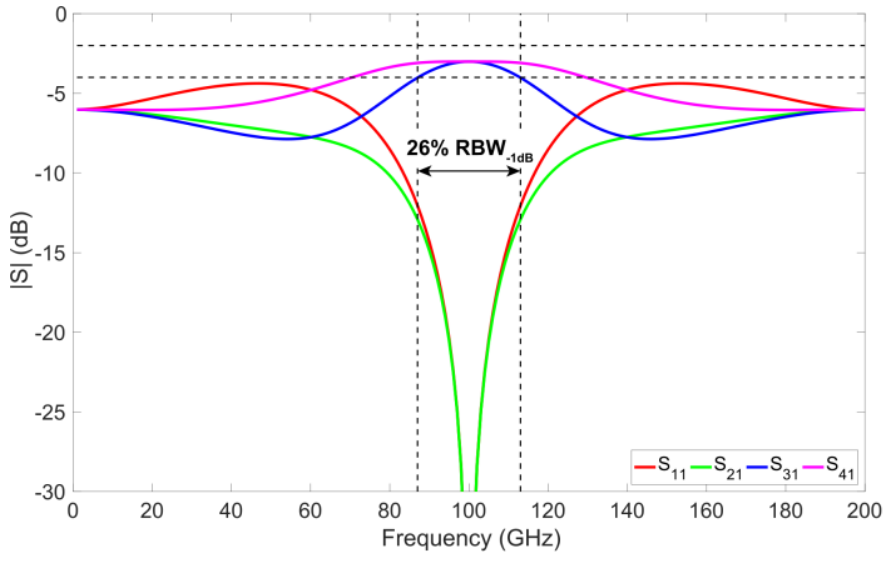

(a)

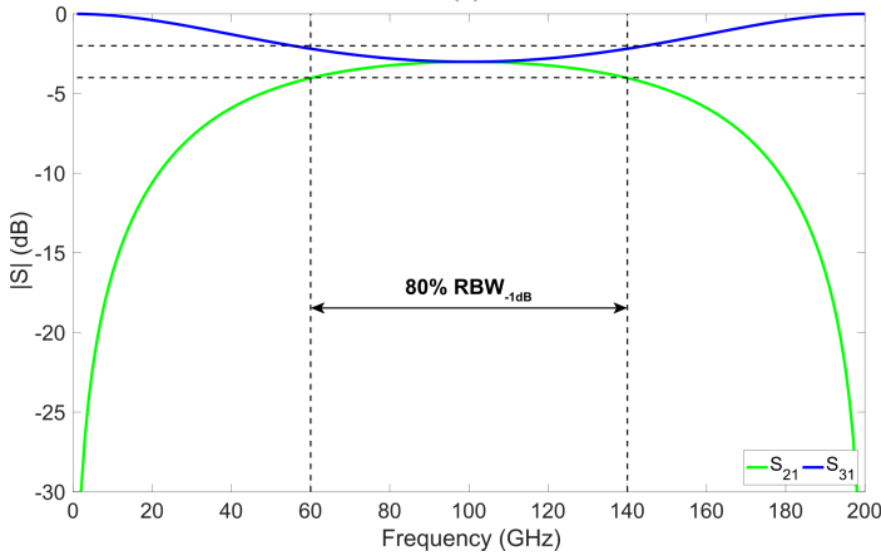

(b)

Fig. 6. S-Parameter magnitude of an ideal 3-dB (a) branchline coupler, and (b) coupled-line coupler.

another designed using coupled lines. Under these considerations, and using a classical architecture, the branchline coupler is composed of four quarter-wavelength transmission lines. If a $50-\Omega 3-\mathrm{dB}$ coupler us considered, two of these transmission lines present a characteristic impedance of $50 \Omega$ while the other pair present a characteristic impedance of $50 / \sqrt{2} \Omega$. On the other hand, the coupled-line coupler is composed of two quarter-wavelength coupled transmission lines whose even- and odd-mode impedances can be derived from

$$
\left\{\begin{array}{l}
Z_{C, e}=Z_{C} \cdot \sqrt{\frac{1+k}{1-k}} \\
Z_{C, o}=Z_{C} \cdot \sqrt{\frac{1-k}{1+k}}
\end{array}\right.
$$

as a function of the coupling coefficient, $k$ (i.e., $1 / \sqrt{2}$ in the case of a $3-\mathrm{dB}$ coupling). Hence, a $50-\Omega 3-\mathrm{dB}$ coupler requires a $Z_{C, e}$ and $Z_{C, o}$ of approximately 120 and $20 \Omega$, respectively.

Fig. 6(a) and Fig. 6(b) display the S-Parameters magnitude of the ideal 3-dB couplers designed with branchline or coupledline architectures, respectively. Note that if a $\pm 1 \mathrm{~dB}$ bandwidth (BW) is defined in the transmission S-parameters, that is $S_{31}$ 
and $S_{41}$ for the branchline coupler, and $S_{31}$ and $S_{21}$ for the coupled-line coupler, respectively, the branchline coupler presents a $26 \%$ of Relative BW (RBW), while the coupled-line coupler shows a RBW of $80 \%$. In addition, the branchline coupler presents high isolation and return loss only for a narrow band of frequencies. On the other hand, an ideal coupled-line coupler shows infinite isolation and matching at any frequency (i.e., infinite BW), and hence not shown in Fig. 6(b). The superiority of the coupled-line coupler can also be observed in terms of its phase shift. If a $\pm 5^{\circ} \mathrm{BW}$ is defined on the phase difference between the coupled and through ports of the coupler, expected to be $90^{\circ}$, (i.e., $\angle S_{31}-\angle S_{41}$ for the branchline coupler, and $\angle S_{31}-\angle S_{21}$, for the coupled-lines coupler), the branchline coupler presents a $34 \% \mathrm{RBW}$, while the coupled-lines coupler presents an infinite BW.

Despite the superior performance of a coupled-line coupler over a branchline coupler, especially when aiming at large bandwidths, their integration in modern silicon technologies remains an issue when using classical transmission line architectures (that is microstrip lines or CoPlanar Waveguides, $\mathrm{CPW}$ ). The main reasons for this difficulty lay on the stringent design rules of advanced integrated technologies (that usually prohibit approaching metals below a certain threshold) and the inhomogeneity of the medium where the electromagnetic (EM) wave propagates. These issues result in different odd- and evemode phase velocities, and hence in a degraded performance of the designed 3-dB couplers, especially in terms of isolation and bandwidth [9].

Several techniques and architectures of coupled-line couplers using microstrip technology have been reported on the literature [10]-[13]. However, many of these techniques [10], [11], [13] rely on the use of the so-called coupled microstrip lines in a broadside configuration to achieve the necessary coupling.

This architecture, asymmetrical by nature, together with the inhomogeneity of the BEOL (i.e., different $\varepsilon_{r, e f f}$ for different BEOL layers) leads to poor directivity and narrow bandwidths. In this scenario, compensation in order to equalize the phase velocity of the even- and odd-modes is necessary to improve the performance of the coupler. For example, authors in [11] propose a lumped LC circuit to improve the behavior of the proposed coupler. With this approach, they are able to achieve isolation levels beyond $20 \mathrm{~dB}$.

To overcome these challenges, the Coupled Slow-wave CPW (CS-CPW) architecture was proposed in [14]. In this article, authors presented the CS-CPW topology and gave broad design

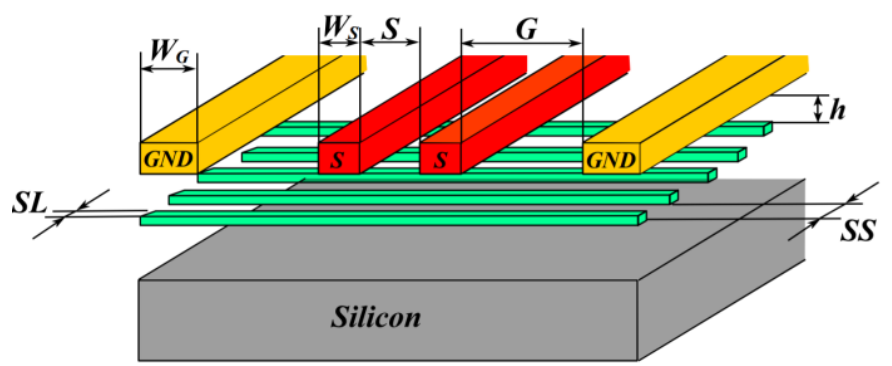

Fig. 7. Representation of the CS-CPW architecture and its geometrical magnitudes. rules. Subsequently, an analytical parametric model was given in [15] together with the design and experimental validation of state-of-the-art mm-wave 3-dB couplers. Indeed, couplers presented in [15] reported the greatest RBW in terms of insertion loss and phase difference as well as a great isolation.

These couplers are composed of a classical coupled CPW structure where electrically floating metallic fingers (or ribbons) have been added transversally to the propagation direction below the signal and ground strips. These ribbons, in the design step, allow tuning the electrical coupling between the strips independently from the magnetic coupling coefficient. A representation of this architecture and the geometric magnitudes that define it is shown in Fig. 7. In addition, cuts can be performed at the center or sides of these ribbons, to tune the electrical coupling coefficient, adding several degrees of freedom for the designer.

Moreover, the addition of the fingers leads to a slow-wave effect (i.e., an artificial increase of the effective dielectric constant $\varepsilon_{\text {reff }}$ ). The increase of $\varepsilon_{\text {reff }}$ reduces the propagation velocity and reduces the necessary physical length to implement a given electrical length, thus leading to more compact structures [16], [17].

The design flexibility and demonstrated performance of the CS-CPW architecture make it very suitable for the proposed Through-Load element implementation.

\section{Loading MOSFET design}

As introduced above, to obtain the desired performance, the load has to present two particular impedances as the response to a control signal. Hence, the nMOS transistor in Fig. 1(a) has to be carefully designed to present these two differentiated states.

In fact, if we consider that the control voltage is a binary digital control that switches the transistor state between the cutoff and the linear regions, two possible scenarios would be possible: (i) a transistor presenting a $50-\Omega$ resistance in its cutoff state and a null resistance when biased into its linear region or, (ii) a transistor presenting an infinite resistance in its cutoff state and a $50-\Omega$ resistance in the linear region. Even though these two options are theoretically possible, the second one is favored hereby as it leads to lower parasitic effects.

To illustrate this choice, let us qualitatively describe the requirements for an nMOS in the common-source configuration shown in Fig. 1. For the sake of simplicity, the gate length is considered as a constant parameter. In this scenario, to satisfy the first combination (i.e., $Z_{\text {load,cut-off }}=50 \Omega$ and $Z_{\text {load,linear }}=0 \Omega$ ) the transistor should be integrated using a very large gate, leading to high capacitive parasitics. Note that these parasitics would only affect the Load state as the Through state would only suffer from a greater phase shift due to these effects. On the other hand, if the second combination is chosen (i.e., $Z_{\text {load,cut-off }}=\infty \Omega$ and $Z_{\text {load,linear }}=50 \Omega$ ) the gate of the transistor can be implemented with a rather narrow width in most of the modern nanometric nodes. This approach leads to reduced parasitic and better performance of the circuit in the Load state.

The reader may note that $Z_{\text {load }}=0 \Omega$ and $Z_{\text {load }}=\infty \Omega$ were stated as possible values for the conductance and cutoff states 


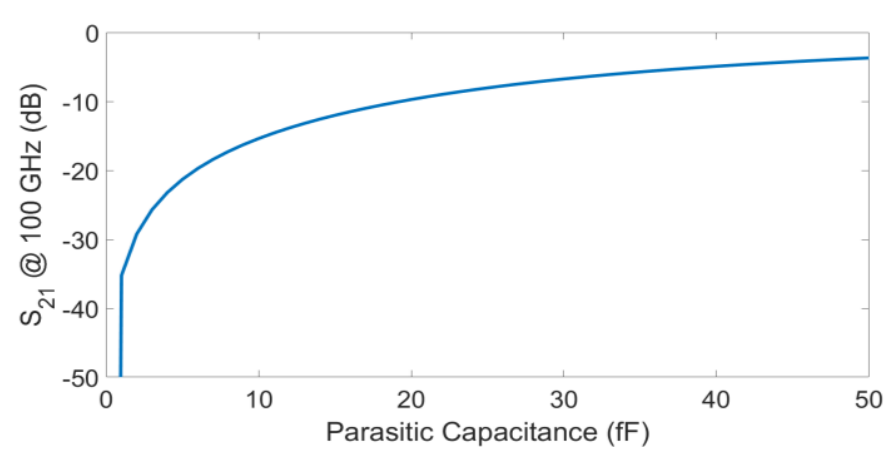

Fig. 8. Magnitude of $S_{21}$ of the Through-Load element at $100 \mathrm{GHz}$ constituted by an ideal $100-\mathrm{GHz} 50-\Omega 3-\mathrm{dB}$ coupler and a MOSFET modelled by an RC network where $R=50 \Omega$ and $C$ is a variable.

of a transistor. Obviously, these are approximations for the ideal desired behavior of the transistor. In a practical device, neither of them represent a realistic scenario. However, these guidelines may be used by the designer in order to determine the best transistor geometry to achieve a given design goal.

On the other hand, as introduced before, it cannot be considered that a MOSFET presents a purely real impedance at its drain level. To illustrate in a simple manner the effect of the MOSFET non-idealities, specially the effect of its parasitic capacitances, let us approximate the behavior of the MOSFET in our proposed application as an equivalent parallel RC network. At the central frequency and considering the results displayed in Fig. 4, the greatest impact of the parasitic capacitance is observed for an input impedance of the loading transistor close to $50 \Omega$ (i.e., Load state), as this capacitance increases the magnitude of $\Gamma_{L}$, which is meant to present a null value in this state.

Fig. 8 represents the $\left|S_{21}\right|$ of the Through-Load element in the Load state as a function of the capacitance of an RC representation of the MOSFET. The figure was obtained using an ideal $50-\Omega 3-\mathrm{dB}$ coupler with a central frequency of 100 $\mathrm{GHz}$ together with the RC representation of the MOSFET (with a resistor $R$ of $50 \Omega$ and a capacitance ranging from 0 to $50 \mathrm{fF}$ ).

Note that the isolation of the Through-Load element is strongly related to the equivalent parasitic capacitance of the MOSFET as seen between the drain and source terminals. In order to minimize this effect, the sizing of the transistor should favor smaller geometries.

\section{Proof-OF-Concept Prototype Design}

In order to demonstrate the feasibility and the on-silicon performance of this architecture a prototype demonstrator was designed and characterized in the laboratory. The prototype was designed in the STM 55-nm BiCMOS. This technology features a Back-End-of-Line (BEOL), schematically shown in Fig. 9, very suitable for the design of high Quality-factor ( $Q$-factor) passive devices.

The prototype was designed for wideband operation around a central frequency of $120 \mathrm{GHz}$. This frequency is placed roughly at the middle of the mm-wave band. Hence, a wideband system with this central frequency will be suitable for applications in most of the frequency band of interest.

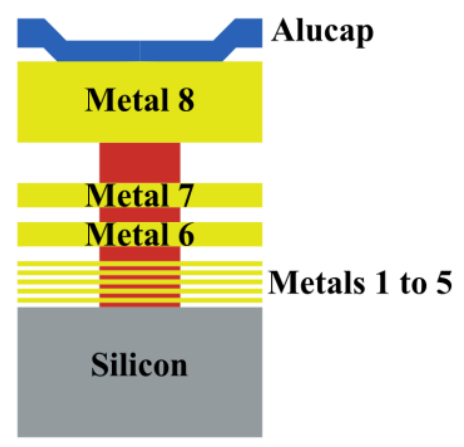

Fig. 9. Representation of the STM 55-nm BEOL.

\section{A. 3-dB Coupler Design and Measurement Results}

As introduced above, the coupler was designed using the CSCPW architecture. For increased electrical coupling, needed to get the 3-dB coupling, cuts were performed on the sides of the floating ribbons. Firstly, this coupler was fabricated as a standalone device, to separately account for its performance in the proposed system. The fabricated coupler was designed using metals 7 and 8 for the signal and ground strips and metal 5 for the floating ribbons. The lateral dimensions were integrated using $W_{S}=2 \mu \mathrm{m}, S=1.8 \mu \mathrm{m}, G=20 \mu \mathrm{m}, W_{G}=$ $15 \mu \mathrm{m}, S S=S L=0.5 \mu \mathrm{m}$, a cut on the ribbon side, $C S$, of 2 $\mu \mathrm{m}$ and a length of $255 \mu \mathrm{m}$. A microphotograph of the fabricated coupler is shown in Fig. 10.

The coupler was measured using a 4-port Anritsu VectorStar MT7838A4 VNA from 1 to $145 \mathrm{GHz}$. A first-tier line-reflectreflect-match (LRRM) [18] was performed on an impedance standard substrate (ISS) calibrating the system up to the probe tips. Subsequently, a second-tier on-wafer multimode thrureflect-line (TRL) calibration [19] was performed, setting the reference planes at the input of the DUT, as shown in Fig. 10.

The measurement results are shown in Fig. 11 together with 3D EM simulations up to $240 \mathrm{GHz}$ obtained using the commercial software ANSYS HFSS. Measurement and simulation results show very good agreement, even though some discontinuities are observed at around $120 \mathrm{GHz}$ for $S_{11}$ and $S_{41}$, which appeared during the second-tier calibration. At $120 \mathrm{GHz}$, the system shows $-3.7 \mathrm{~dB}$ at the through port (i.e.,

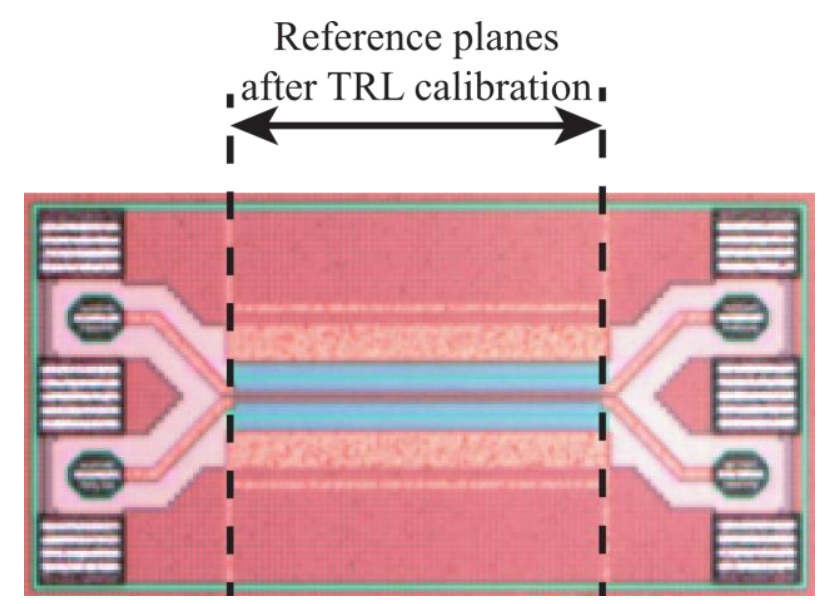

Fig. 10. Microphotograph of the fabricated 3-dB coupler and reference planes after the multimode TRL calibration. 


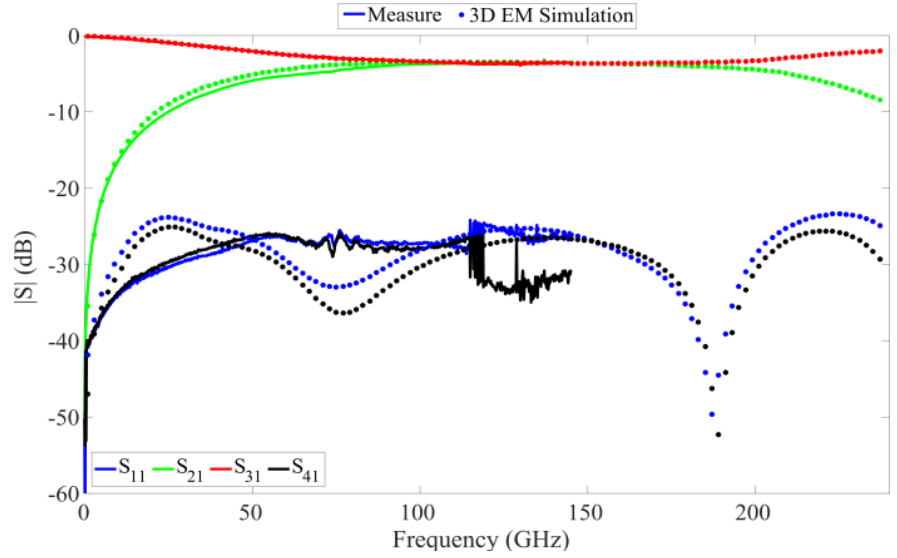

Fig. 11. Measured (solid line) and simulated (dots) S-Parameter magnitude of the $3-\mathrm{dB}$ coupler.

port 3), $-3.6 \mathrm{~dB}$ at the coupled port (i.e., port 2), and an isolation and return loss greater than $25 \mathrm{~dB}$.

The other important parameter in the design of a $3-\mathrm{dB}$ coupler is the phase difference between its through and coupled ports. The result of this measurement is shown in Fig. 12 for the measured and simulated data sets. Again, very good agreement is observed between simulation and measurement results. At $120 \mathrm{GHz}$, the measured coupler shows a phase difference of $94^{\circ}$.

Finally, thanks to the slow-wave effect, an effective permittivity $\varepsilon_{r, e f f}$ of 5 is achieved, leading to a $30 \%$ increase as compared to microstrip structures in the same technology, and a subsequent miniaturization effect.

These results show that the CS-CPW architecture is very suitable for the design of high-performance 3-dB couplers on integrated technologies, necessary for the proposed application. As compared to the behavior of an ideal coupler, described in section II, the measured coupler shows a similar behavior with wideband high isolation, return loss and a relatively flat phase shift between its through and coupled outputs.

\section{B. MOSFET Design and Measurement Results}

The switching element was integrated using an nMOS transistor with a width of $7.38 \mu \mathrm{m}$, divided in three fingers, and a length of $55 \mathrm{~nm}$. The transistor was sized in order to achieve a minimum $\mathfrak{J}\left(Z_{\text {load }}\right)$ and a maximum $\mathfrak{R}\left(Z_{\text {load }}\right)$ in the OFFstate (i.e., $V_{G}=0 \mathrm{~V}$ ) while achieving an $\Re\left(Z_{\text {load }}\right) \approx 50 \Omega$ and

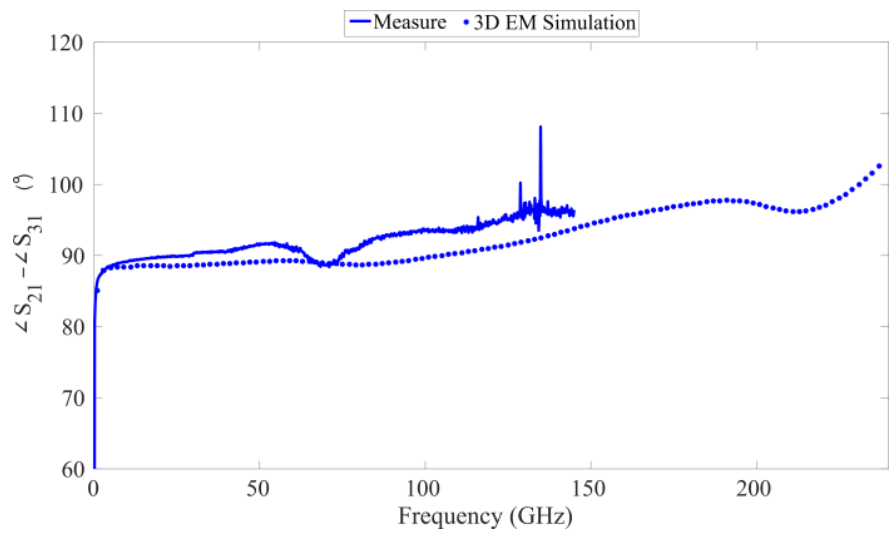

Fig. 12. Measured (solid line) and simulated (dots) phase difference between the through and coupled ports, as seen from the input for the designed 3-dB coupler. maintaining a minimum $\mathfrak{\Im}\left(Z_{\text {load }}\right)$ in the $\mathrm{ON}$-state (i.e., $V_{G}=$ $V_{D D}$, or $1.2 \mathrm{~V}$ in this technology). In addition, a high-value resistance, $R_{b}$, and a decoupling capacitance, $C_{d}$, were placed at the gate of the transistor, as shown in Fig. 1. The role of the resistance, which was integrated using a high-resistivity resistor presenting $60 \mathrm{k} \Omega$ of resistance, is to isolate the biasing circuitry from the RF signal. On the other hand, the capacitor was integrated using a Metal-Oxide-Metal (MOM) capacitor presenting a capacitance of $300 \mathrm{fF}$.

The proposed switching element was integrated as a standalone device for characterization purposes and measured using two different VNAs, a R\&S ZVA67 with ZVA-Z110E extenders from $250 \mathrm{MHz}$ to $110 \mathrm{GHz}$ and a R\&S ZVA27 with ZC220 extenders from 140 to $220 \mathrm{GHz}$. An on-wafer TRL calibration [20] was performed in both measurement setups, setting the reference planes at the input of the DUT. The Line standard for the lower band presented a $315 \mu \mathrm{m}$ additional length, as compared to the Through standard (i.e., 90 degrees of electrical length at around $110 \mathrm{GHz}$ ). Hence, if we consider the calibration to be valid for those frequencies where the additional length of the Line is between 10 and 170 degrees, the performed calibration can be considered to be valid between around 10 and $110 \mathrm{GHz}$-and beyond, even if not used. On the other hand, the upper band was calibrated using a Line standard presenting an additional length of $150 \mu \mathrm{m}$ (i.e., 90 degrees of electrical length at around $220 \mathrm{GHz}$ ), which led to an accurate calibration throughout the whole G-band (i.e., 140-220 GHz).

Fig. 13 presents the post-layout and measurement results of the $\left|S_{11}\right|$ at the input of the switching element, in the $250 \mathrm{MHz}$ to $220 \mathrm{GHz}$ band. Both, post-layout simulation and measurement show relatively good agreement. Some disagreement is observed in the lower part of the considered band for the ON-state, where the electrical length of the Line standard becomes increasingly small and sensitivity is lost.

Within the considered band (i.e., 10-220 GHz), measurements and post-layout simulation report an $\left|S_{11}\right|$ ranging from $-50 \mathrm{mdB}$ to $-1.1 \mathrm{~dB}$ (disregarding the unphysical behavior of $S_{11}$ occurring between 80 and $110 \mathrm{GHz}$, caused by the uncertainty of the VNA performing this measurement) for the OFF-state of the switching element. On the other hand, in this frequeny range and for the $\mathrm{ON}$-state, simulation reported an $\left|S_{11}\right|$ ranging from -22 to $-12 \mathrm{~dB}$ while measurement reports -35 to $-8 \mathrm{~dB}$ of $\left|S_{11}\right|$. Note that some disagreement is seen

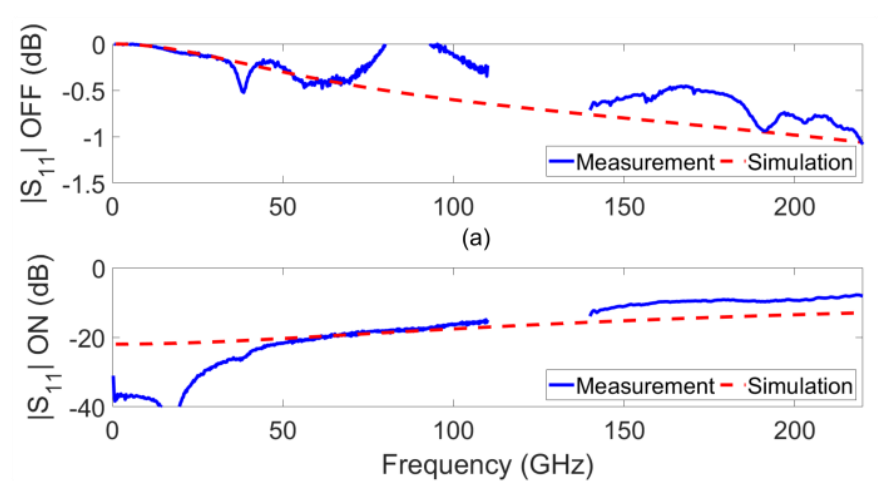

(b)

Fig. 13. Measured (solid line) and post-layout simulation (dashes) of the: (a) $\left|S_{11}\right|$ of the switching element in its OFF-state (i.e., $V_{G}=0 \mathrm{~V}$ ) and (b) ON-state (i.e., $V_{G}=1.2 \mathrm{~V}$ ). 


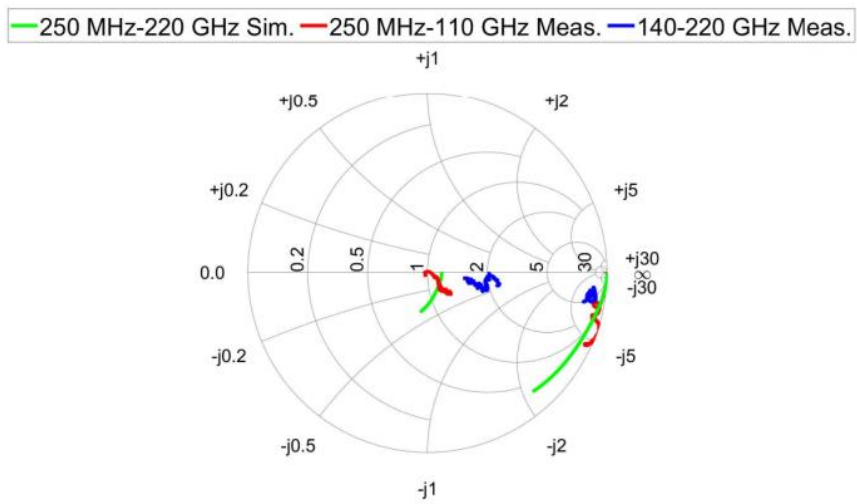

Fig. 14. Smith chart representation of the Load standard for its OFF (edge of the chart) and $\mathrm{ON}$-states (center of the chart). The red lines present the 250 $\mathrm{MHz}-110 \mathrm{GHz}$ measured frequency band, blue lines the $140-220 \mathrm{GHz}$ measured frequency band and the green lines represent the post-layout simulation-based results in the $250 \mathrm{MHz}-220 \mathrm{GHz}$ band.

between measurement and simulation in the upper part of the considered band. It is worth saying that the models in the Process Design Kit (PDK) have not been validated at these high frequencies and hence, some disagreement might be expected. In any case, the observed differences remain relatively contained.

Finally, Fig. 14 presents the Smith Chart representation of the measured $S_{11}$ at the input of the MOSFET after deembedding. Note that again, as frequency increases, divergence is observed. The simulation and $250 \mathrm{MHz}-110 \mathrm{GHz}$ datasets show good agreement, while in the $140-220 \mathrm{GHz}$ frequency band, simulation is less close to the measurement due to the limited accuracy of the PDK models.

\section{Through-Load Measurement Results}

Fig. 15 shows a microphotograph of the complete ThroughLoad system. The complete system, without access lines, RF and DC pads, has a footprint of $0.02 \mathrm{~mm}^{2}$. The Through-Load element was measured using the same setup and measurement conditions employed for the MOSFET and presented above. In addition, the linearity was studied with input powers in the -20 to $3 \mathrm{dBm}$ range, as limited by our test equipment. Within this range, the device showed a linear behavior. On the other hand, simulations show no significant compression with input powers up to $20 \mathrm{dBm}$.

Fig. 16 presents the measured (solid line) and post-layout simulations (dashed line) of the reflection coefficient

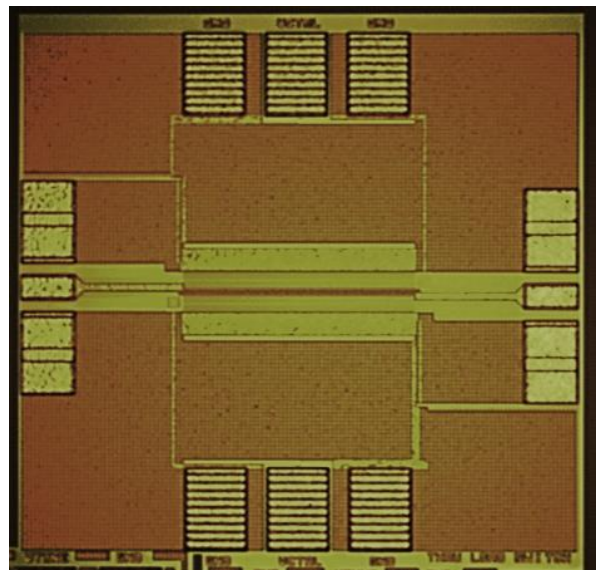

Fig. 15. Microphotgraph of the Through-Load element.

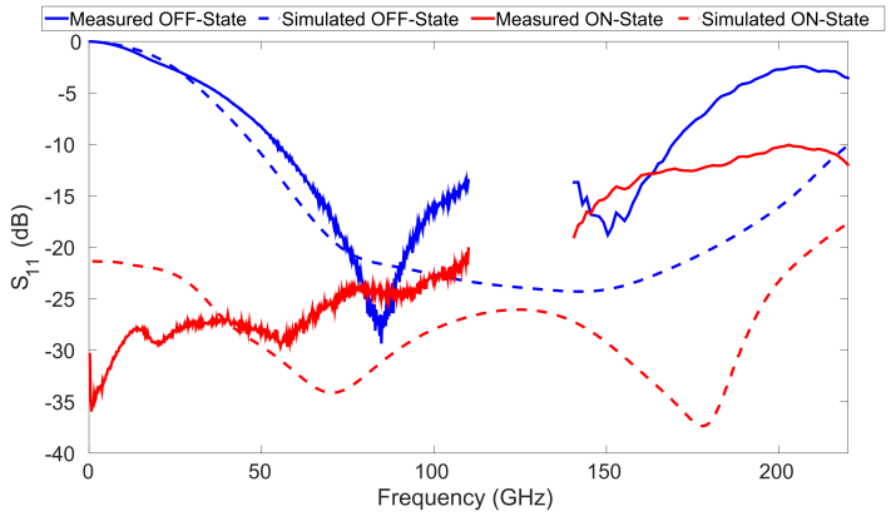

Fig. 16. Measured (solid line) and post-layout simulation (dashes) of $S_{11}$ of the Through-Load system in its ON-state (i.e., $V_{G}=1.2 \mathrm{~V}$ ) and OFF-state (i.e., $\left.V_{G}=0 \mathrm{~V}\right)$

magnitude of the Through-Load system in the $250 \mathrm{MHz}$ to 220 $\mathrm{GHz}$ frequency band for both, ON- and OFF-states. Both measured datasets present relatively good agreement with their simulated counterparts. Again, some disagreement can be observed in the upper band due to the operation limits of the employed MOSFET models.

The proposed system shows a bandwidth of $115 \mathrm{GHz}$, from 55 to $170 \mathrm{GHz}$, if a return loss greater than $10 \mathrm{~dB}$ is considered. If the central frequency is considered to be the median between those values (i.e., approximately $112 \mathrm{GHz}$ ), the proposed system shows a Relative Bandwidth (RBW) of around 100\% and hence presents a wideband solution, as intended.

Finally, Fig. 17 presents the post-layout simulation (dashed line) and measured (solid line) insertion loss of the ThroughLoad system in both, the ON- and OFF-states. Within the 55$170 \mathrm{GHz}$ band, the measured and simulated insertion loss range between 0.6 and $1.6 \mathrm{~dB}$ in its OFF-state (i.e., behaving as a Through connection). On the other hand, the measured ONstate (i.e., behaving as a $50-\Omega$ load) insertion loss ranges between 24 and $14 \mathrm{~dB}$, similarly to the simulated dataset.

The device was integrated in a prototype run and hence we have very low number of samples from the same area of a single wafer. Process variations in our fabricated samples are negligible and do not lead to significant performance variations from one fabricated device to another. However, to get some insight into the effect of process variations, we performed a Monte Carlo (MC) analysis using the process variation and

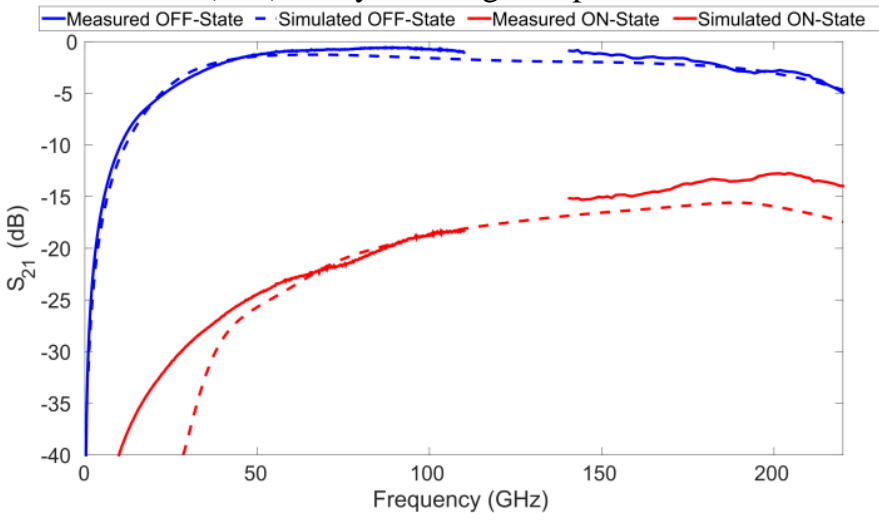

Fig. 17. Measured (solid line) and post-layout simulation (dashes) of $S_{21}$ of the Through-Load system in its ON-state (i.e., $V_{G}=1.2 \mathrm{~V}$ ) and OFF-state (i.e., $\left.V_{G}=0 \mathrm{~V}\right)$. 


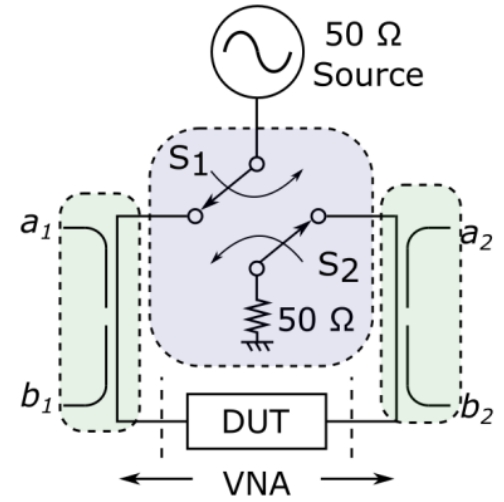

Fig. 18. Schematic representation of a VNA. The transfer-switch is in blue and the directional couplers are in green.

mismatch models provided in the Process Design Kit of the selected 55nm BiCMOS technology. This way, we generated 1000 instances of the Through-Load element. This analysis showed that, in the OFF-state (ON-state), the standard deviation of the Return Loss is around $0.4 \mathrm{~dB}(0.03 \mathrm{~dB})$ while the standard deviation of the Insertion Loss is around $0.01 \mathrm{~dB}(1.6 \mathrm{~dB}) . \mathrm{In}$ addition, similar performance variations were observed for the simulated $0-100{ }^{\circ} \mathrm{C}$ temperature range. Hence, this architecture, integrated in the 55-nm BiCMOS technology, is robust against process and temperature variations.

\section{APPLICATIONS}

Due to the large bandwidth, insertion loss difference between $\mathrm{ON}$ - and OFF-states together with the reduced losses in the OFF-state, multiple applications can take advantage of the proposed system. In particular, this paper will discuss two potential applications: (i) a Transfer-Switch, and (ii) an integrated attenuator.

\section{A. Transfer Switch}

A transfer switch is a device integrated within a multi-port VNA that is in charge of switching the port to whom the input wave is applied and the one acting as a 50- $\Omega$ load. A schematic representation of such device, together with the couplers of a 2 port VNA is shown in Fig. 18.

The operation of the transfer switch in an architecture like the one shown in Fig. 18 allows the measurement of the 4 scattering parameters describing the behavior of a 2-port system. First, the transfer switch is in the position shown in this figure, and thus injecting the signal of the $50-\Omega$ source on the left port of the DUT and loading its right port to $50 \Omega$, allowing the measurement of $S_{11}$ (i.e., $b_{1} / a_{1}$ ) and $S_{21}$ (i.e., $b_{2} / a_{1}$ ). Then, the position of the switches in the transfer switch are inverted, injecting the signal on the right port of the DUT and loading its left port to $50 \Omega$, permitting the measurement of $S_{12}$ (i.e., $b_{1} / a_{2}$ ) and $S_{22}$ (i.e., $b_{2} / a_{2}$ ).

Note that this is a key element in a multi-port VNA. Hence, enabling the integration of multi-port VNA for on-wafer characterization and BIST applications demands the design of transfer switches. The design of mm-Wave transfer switches is still a major bottleneck for the integration of multi-port VNA solutions, as no on-silicon transfer switch, to the best of the authors' knowledge, has been reported in the literature up to this date.

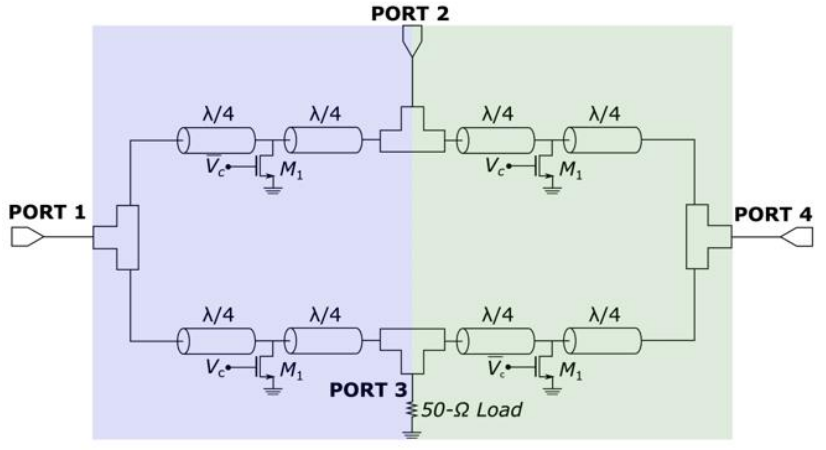

Fig. 19. Possible implementation of a transfer switch in the mm-Wave frequency band.

In the mm-Wave domain, a practical integrated transfer switch could be implemented as shown in Fig. 19 (i.e., using two Single-Pole Double-Throw, SPDT, switches highlighted in blue and green, and a $50-\Omega$ load). However this architecture has several disadvantages. First, it is a relatively narrow-band solution as its bandwidth is limited by the $\lambda / 4$ transmission lines. In addition, it presents a relatively large insertion loss. To illustrate this issue, current state-of-the-art MOS-based SPDT switches present around 3-4 dB of insertion loss [21]-[25]. In addition, if high-performance is targeted, a co-design of the transfer switches and the 50- $\Omega$ load has to be envisioned. Otherwise, the parasitics introduced may lead to a malfunction of the system.

In this context, the Through-Load system represents an attractive alternative for the implementation of this function as the co-design between coupler and $50-\Omega$ load is inherently considered. For its implementation in a complete 2-port VNA architecture, the scheme shown in Fig. 20 can be proposed. Note that two Through-Load elements are required for this implementation and an additional power divider is required. An ideal power divider delivers half of the input power to each of its outputs (i.e., $-3 \mathrm{~dB}$ of the input power to each Through-Load element). To maintain the bandwidth of the system, the coupled-line 3-dB coupler used for the implementation of the Through-Load element can be reused to implement the power divider function, eliminating the need for additional design steps.

It is important to note that a fraction of the power would be lost in the Through-Load system that is in its ON-state (i.e., ideally, 3-dB). However, this loss together with the losses of the Through-Load element - around 0.6-1.6 dB, in this design -

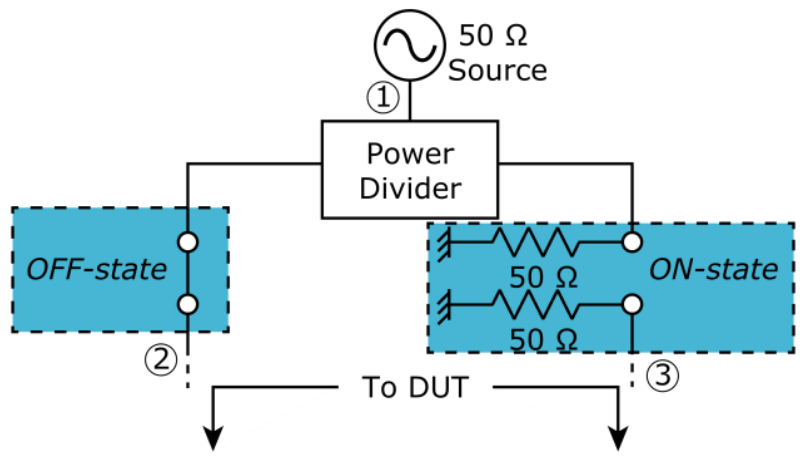

Fig. 20. Possible implementation of a transfer switch using the proposed Through-Load architecture. 


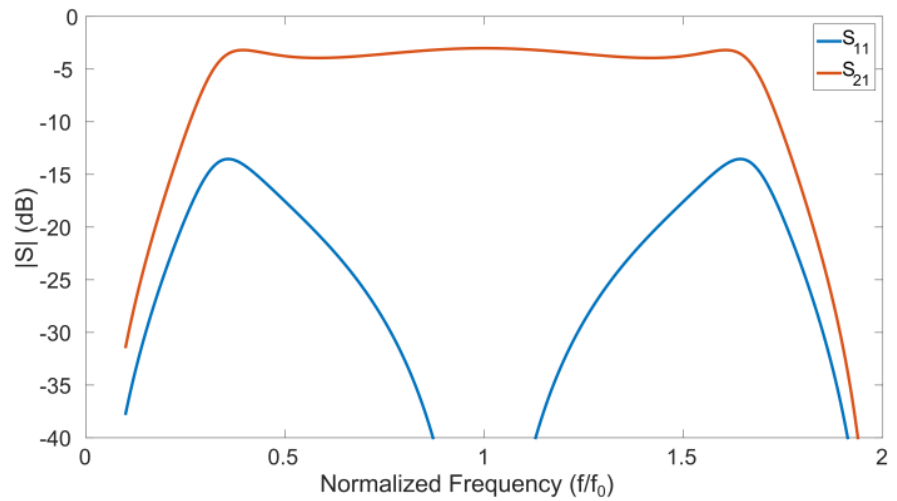

Fig. 21. S-Parameters of the proposed transfer switch architecture using ideal elements and a $3-\mathrm{dB}$ coupled-line coupler to implement the power divider.

represents the same loss that the current SPDT solutions present [21]-[25], while improving their bandwidth and avoiding the additional step of accurate $50-\Omega$ load design that they would require.

For instance, if ideal elements are considered and a 3-dB coupled lines coupler is used for the implementation of the power divider, the S-Parameter magnitude of the proposed solution can be traced versus the normalized frequency where $f_{0}$ is the central frequency of the coupler, as shown in Fig. 21. Note that port 1 corresponds to the output of the $50-\Omega$ source in Fig. 20 and port 2 is connected to the output of the ThroughLoad element in the OFF-state (i.e., left port of the DUT in Fig. 20.

As seen in Fig. 21, such a solution would present a return loss greater than $13 \mathrm{~dB}$ for any frequency and an insertion loss lower than $5 \mathrm{~dB}$ from normalized frequencies ranging between 0.3 and 1.7. Isolation between the two ports of the DUT (i.e., ports 2 and 3 in Fig. 20) is not seen in Fig. 21 as its magnitude using ideal elements is null at any frequency. A similar behavior would be observed for the return loss seen at the output of the DUT meant to be loaded by $50 \Omega$ (i.e., $\left|S_{33}\right|=0$ ).

To put this idea into perspective using real devices, let us use the measurements to implement the circuit in Fig. 20. For this purpose, the power divider is integrated using the $3-\mathrm{dB}$ coupler presented in section III.A. and the Through-Load elements presented in section III.C. Note that only 1-145 GHz measurements could be carried out for the 3 -dB coupler. Hence, the results beyond $140 \mathrm{GHz}$ reported hereby are carried out

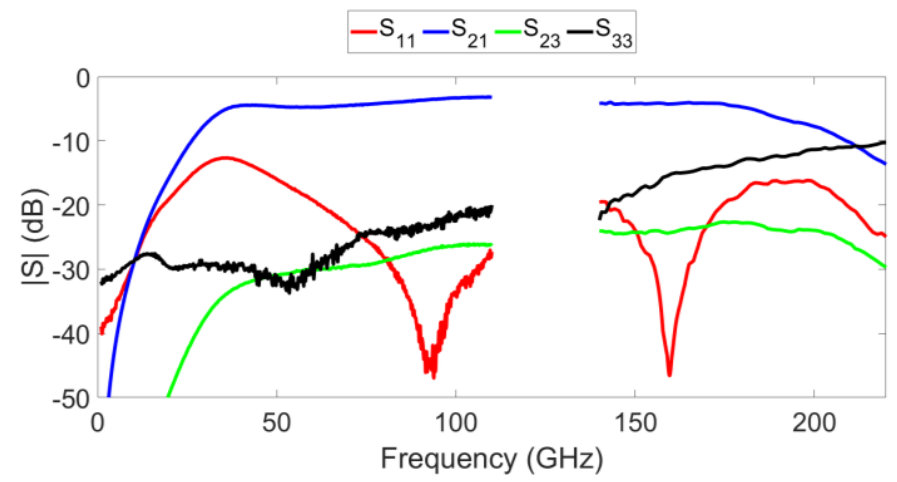

Fig. 22. S-Parameters of the proposed transfer switch architecture using measured data. Results beyond $110 \mathrm{GHz}$ were obtained by using the simulations of the 3-dB coupler with the measurement of the Through-Load element.
TABLE I

STATE-OF-THE-ART TRANSFER SWITCHES

\begin{tabular}{c|c|c|c} 
Ref & {$[26]$} & {$[26]$} & This work \\
\hline \hline Freq. (GHz) & $140-220$ & $140-195$ & $\mathbf{3 5 - 1 8 0}$ \\
\hline$\left|S_{11}\right|(\mathrm{dB})$ & $>10$ & $>10$ & $>\mathbf{1 3}$ \\
\hline$\left|S_{21}\right|(\mathrm{dB})$ & $4.5-5.9$ & $5.7-7$ & $\mathbf{3 . 2 - 5}$ \\
\hline$\left|S_{23}\right|(\mathrm{dB})$ & $20-33$ & $27-44$ & $\mathbf{2 4 - 3 3}$ \\
\hline$\left|S_{33}\right|(\mathrm{dB})$ & $10-32$ & $13-18$ & $\mathbf{1 3 - 3 2}$ \\
\hline $\begin{array}{l}\text { \# of DC } \\
\text { voltages }\end{array}$ & 2 & 2 & $\mathbf{1}$ \\
\hline $\begin{array}{c}\text { Area }\left(\mathrm{mm}{ }^{2}\right) \\
\end{array}$ & 0.58 & 0.69 & $\approx \mathbf{0 . 0 6} \mathbf{1}^{\mathbf{1}}$ \\
& & &
\end{tabular}

using the simulation-based results for the coupler. As this device was not fabricated, the interconnections are considered to be ideal. However, the geometry of the building blocks allows to directly connect them with practically zero-length interconnections.

These results are shown in Fig. 22, which displays the magnitude of the most relevant S-Parameters for this application across the 1-220 GHz frequency range. In this configuration, at a $110 \mathrm{GHz}$, the proposed system presents an insertion loss of $3.2 \mathrm{~dB}$, really close to its ideal $3 \mathrm{~dB}$ of losses shown in Fig. 21. At this frequency, the isolation (i.e., $\left|S_{23}\right|$ ) is of $24 \mathrm{~dB}$, its return loss of $27 \mathrm{~dB}$ at the RF source level (i.e., $\left.S_{11}\right)$. Finally, the port of the DUT that is meant to be loaded by $50 \Omega$, would effectively see a load close to this value, as the return loss at this port, $S_{33}$, is of $20 \mathrm{~dB}$, at $110 \mathrm{GHz}$.

In addition to the high performance observed at $110 \mathrm{GHz}$, another great advantage of this architecture for the implementation of transfer switches is its large bandwidth. Indeed, the insertion loss is lower than $5 \mathrm{~dB}$ in the $35-180 \mathrm{GHz}$ frequency band. Moreover, the isolation is below $24 \mathrm{~dB}$ for any frequency in the considered band. Throughout the whole considered band, the return loss at source level and the loaded side of the DUT is greater than 13 and $10 \mathrm{~dB}$, respectively.

To the best of authors' knowledge, currently, only one mmwave transfer switch has been reported in the literature in a silicon-based technology [26]. This work reports two implementations of transfer switches using different architectures but mainly based on the schematic view shown in Fig. 19.

A comparison between the results reported in [26] and the results obtained in this paper is shown in Table I. The proposed architecture is superior in most of the analyzed metrics, it shows a much greater bandwidth, reduced losses, better $50-\Omega$ matching, increased control simplicity and a much reduced footprint. In terms of isolation and return loss both 
TABLE II

STATE-OF-THE-ART ATTENUATORS

\begin{tabular}{|c|c|c|c|c|c|c|c|c|}
\hline Ref & Tech. & Freq. (GHz) & $\begin{array}{l}\text { Att. Range } \\
\text { (dB) }\end{array}$ & $\mathrm{RL}(\mathrm{dB})$ & $\begin{array}{c}\text { 1-dB CP } \\
(\mathrm{dBm})\end{array}$ & Power (mW) & $\begin{array}{l}\text { \# of DC } \\
\text { voltages }\end{array}$ & Area $\left(\mathrm{mm}^{2}\right)$ \\
\hline [27] & $0.13-\mu \mathrm{m}$ CMOS & DC-2.5 & $1.5-42$ & $>8.2$ & 2.5 & 1.9 & 5 & N/A \\
\hline$[28]$ & $\begin{array}{c}0.18-\mu \mathrm{m} \\
\text { BiCMOS }\end{array}$ & $10-67$ & $13-53$ & $>8.4$ & 0 & 0 & 5 & 0.76 \\
\hline [29] & $0.8-\mu \mathrm{m}$ CMOS & DC-0.9 & $3-31$ & $>9$ & 5 & 12 & N/A & 1.57 \\
\hline [30] & $0.18-\mu \mathrm{m}$ CMOS & DC-14 & $10-40$ & $>10$ & 15 & 0 & 8 & 0.5 \\
\hline [30] & $0.18-\mu \mathrm{m}$ CMOS & $8-12$ & $10-40$ & $>10$ & 13 & 0 & 8 & 0.34 \\
\hline$[31]$ & GaAs & $0.045-50$ & $3-70$ & $>10$ & N/A & 0 & 14 & 5.8 \\
\hline$[32]$ & $\begin{array}{c}0.12-\mu \mathrm{m} \\
\text { BiCMOS }\end{array}$ & $10-50$ & $2-13$ & $>9$ & 4 & 0 & 12 & 0.15 \\
\hline$[33]$ & 65-nm CMOS & $10-50$ & $5-18$ & $>8.7$ & 15 & 0 & 12 & 0.19 \\
\hline [33] & 65-nm CMOS & $15-43$ & $4-17$ & $>8.8$ & 14 & 0 & 12 & 0.29 \\
\hline his work & 55-nm BiCMOS & $55-170$ & $0.6-20$ & $>10$ & $>\mathbf{3}$ & $\mathbf{0}$ & 1 & 0.02 \\
\hline
\end{tabular}

architectures present similar performance. Hence, the proposed architecture presented hereby appears as a major solution for the implementation of mm-wave transfer switches in integrated technologies, which could lead to new characterization paradigms.

\section{B. Attenuator}

Attenuators are a ubiquitous element in measurement setups, as measurement systems often need to operate in relatively lowpower conditions. Hence, for DUTs whose output/input power is high, an attenuation scheme is required to protect the measurement systems.

Integrated attenuators [27]-[32] have been widely studied in the past years. However, very few demonstrators in the $\mathrm{mm}$ Wave band have been reported using silicon-based technologies [28], [32]. Most of the reported designs [28]-[33], require multiple control voltages as different stages aiming at different attenuation levels are designed in a discrete-control perspective. In addition, some of these works [27], [29] use amplification schemes to counteract the large losses of the proposed attenuator in its minimum attenuation state.

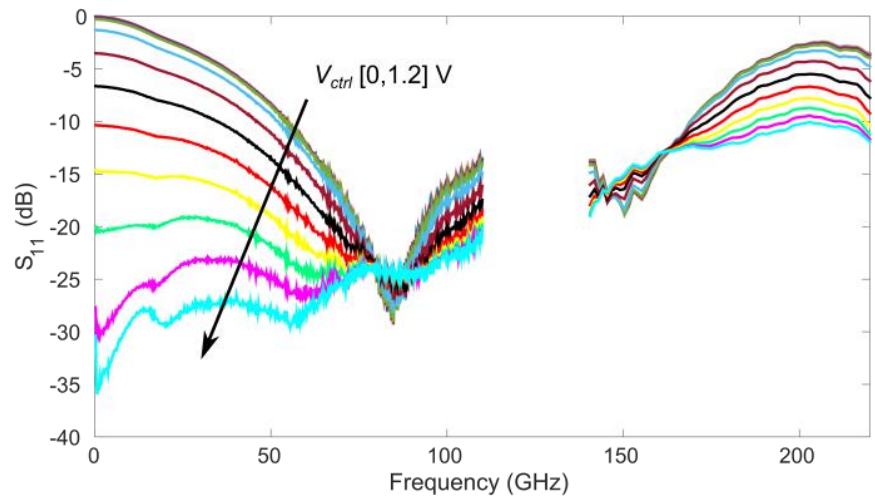

Fig. 23. Measured return loss magnitude of the through-load element with $V_{G}=$ [0 - 1.2] $\mathrm{V}$ in the $250 \mathrm{MHz}-220 \mathrm{GHz}$ band.
In the previous sections of this document, only the so-called ON- and OFF-states (i.e., $V_{G}$ equals to $V_{D D}$ and $0 \mathrm{~V}$, respectively) were explored. However, a new functionality appears when the voltages ranging between these two states are considered.

In this line, we consider the setup presented in section III and sweep $V_{G}$ from 0 to $1.2 \mathrm{~V}$ with a $100 \mathrm{mV}$ step. Fig. 23 presents the $\left|S_{11}\right|$ measurement in the $250 \mathrm{MHz}$ to $220 \mathrm{GHz}$ band. In the previously considered bandwidth of the Through-Load switch element (i.e., $55-170 \mathrm{GHz}$ ), the system respects the $10 \mathrm{~dB}$ return loss condition imposed for the bandwidth consideration for any $V_{G}$ state.

Fig. 24 shows the obtained results for the $\left|S_{21}\right|$, obtained under the same conditions as the previously presented results. It can be noted that an attenuator-like behavior is observed. This behavior is observed over a large bandwidth and can be continuously tuned using the control voltage $V_{G}$. In the considered bandwidth of the Trough-Load element, the system provides a tunable attenuation between 1.6 and $14 \mathrm{~dB}$ in its

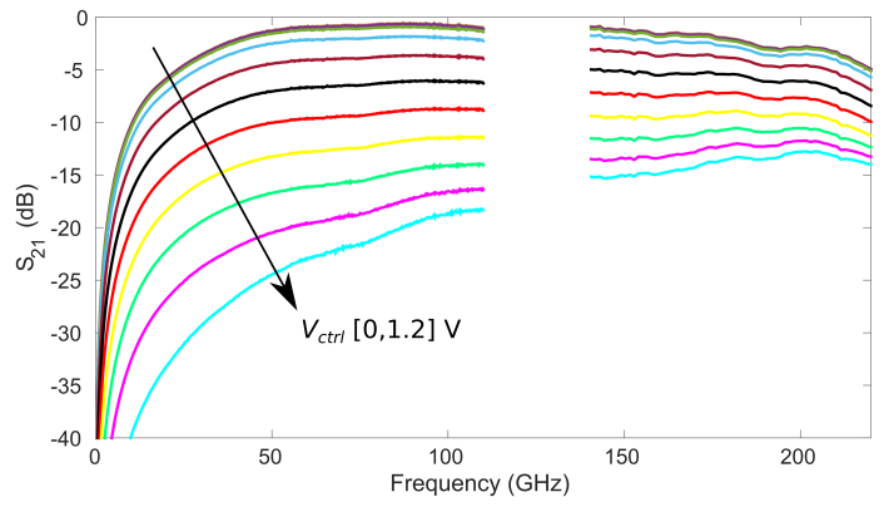

Fig. 24. Measured insertion loss magnitude of the through-load element with $V_{G}=[0-1.2] \mathrm{V}$ in the $250 \mathrm{MHz}-220 \mathrm{GHz}$ band. 
narrower point (i.e., $170 \mathrm{GHz}$ ). However, at around $90 \mathrm{GHz}$, the attenuation can range between 0.6 and more than $20 \mathrm{~dB}$.

The proposed Through-Load is a passive system that has the advantage of requiring solely one control voltage that can, in addition, be tuned in a continuous manner to, in its turn, vary the attenuation level as a continuous function of $V_{G}$. In addition, if greater levels of attenuation are required, multiple instances of the proposed element can be easily cascaded, which would in turn be controlled by the same $V_{G}$ control voltage. If this strategy is adopted, disregarding the interconnection parasitics, the insertion loss for each state of the through-load system would be a linear (in $\mathrm{dB}$ ) function of the number of cascaded Through-Load systems.

For instance, if the measured Through-Load system is considered and the interconnection parasitics are disregarded, when cascading three Through-Load systems an attenuation range between $1.8 \mathrm{~dB}$ and $60 \mathrm{~dB}$ could be achieved, at $90 \mathrm{GHz}$. This considered structure would only require a single control voltage and would only represent a compact footprint of 0.06 $\mathrm{mm}^{2}$.

To put the obtained results into perspective, Table II presents the results of the proposed attenuator together with the current state-of-the-art proposals for the implementation of this circuit. First, note that the proposed system presents the highest operating frequency and an ultra-wideband coverage. In addition, it presents the most reduced losses in its lowattenuation state. Even though it presents a moderate attenuation in its maximum attenuation state, its reduced footprint (i.e., around a 90\% reduction to the smallest implementation in the considered state-of-the-art) together with its reduced losses makes it an excellent candidate for being cascaded with several instances of the same element, as introduced before. Moreover, its biasing simplicity, power handling capabilities and passive configuration makes it an optimal candidate for the implementation of $\mathrm{mm}$-Wave and sub- $\mathrm{THz}$ attenuators.

\section{CONCLUSIONS}

This paper proposes a novel on-chip Through-Load element for integrated $\mathrm{mm}$-wave applications. The proposed element offers a programmable behavior that can be switched from a 50 $\Omega$ load to a Through connection using a single DC control voltage. The functionality of the proposed element is analytically studied and detailed guidelines are provided for its design in advance nanometric integrated technologies.

A prototype demonstrator in STMicroelectronics $55-\mathrm{nm}$ BiCMOS technology has been fabricated and characterized in the laboratory to show the feasibility and performance of the proposed Through-Load element. On-silicon results at $90 \mathrm{GHz}$ demonstrate an insertion loss ranging from $0.6 \mathrm{~dB}$ to $20 \mathrm{~dB}$ as a function of $V_{G}$, and a return loss of around $25 \mathrm{~dB}$. In addition, the proposed system shows an ultra-wide bandwidth of 115 $\mathrm{GHz}$, considering a return loss greater than $10 \mathrm{~dB}$, which represents a relative bandwidth of around $100 \%$.

Finally two possible applications of the proposed ThroughLoad element are outlined: (i) a building block for a transferswitch function, (ii) an attenuator. Comparisons are carried out with the current state-of-the-art implementations of these circuits, showing the potential of the proposed architecture.

\section{REFERENCES}

P. Chevalier et al. " $\mathrm{SiGe}$ BiCMOS Current Status and Future Trends in Europe," in 2018 IEEE BiCMOS and Compound Semiconductor Integrated Circuits and Technology Symposium, BCICTS 2018, 2018, pp. 64-71, doi: 10.1109/BCICTS.2018.8550963.

[2] U. Stumper, "Uncertainty of VNA S-parameter measurement due to non-ideal TMSO or LMSO calibration standards," Adv. Radio Sci., vol. 1, no. 2, pp. 1-8, 2003, doi: 10.5194/ars-1-1-2003.

[3] J. M. Cusack, S. M. Perlow, and B. S. Perlman, "Automatic Load Contour Mapping for Microwave Power Transistors," IEEE Trans. Microw. Theory Tech., vol. 22, no. 12, pp. 1146-1152, 1974, doi: 10.1109/TMTT.1974.1128456.

[4] S. Bouvot et al., "A D-band tuner for in-situ noise and power characterization in BiCMOS $55 \mathrm{~nm}$," in SiRF 2017 - 2017 IEEE 17th Topical Meeting on Silicon Monolithic Integrated Circuits in RF Systems, 2017, pp. 103-106, doi: 10.1109/SIRF.2017.7874384.

[5] W. Aouimeur et al., "A Fully In-Situ Reflectometer in G band in 55 $\mathrm{nm}$ SiGe BiCMOS," in International Workshop on Integrated Nonlinear Microwave and Millimetre-Wave Circuits, INMMIC 2018 - Proceedings, 2018, pp. 1-3, doi: 10.1109/INMMIC.2018.8430015.

[6] A. Serhan, E. Lauga-Larroze, and J. M. Fournier, "CommonBase/Common-Gate Millimeter-Wave Power Detectors," IEEE Trans. Microw. Theory Tech., vol. 63, no. 12, pp. 4483-4491, 2015, doi: 10.1109/TMTT.2015.2496220.

[7] M. Margalef-Rovira et al., "Mm-Wave through-load switch for insitu vector network analyzer on a 55-nm BiCMOS technology," in NEWCAS 2020 - 18th IEEE International New Circuits and Systems Conference, Proceedings, 2020, pp. 82-85, doi: 10.1109/NEWCAS49341.2020.9159829.

[8] R. K. Mongia, J. Hong, P. Bhartia, and I. J. Bahl, RF and microwave coupled-line circuits. Artech house, 2007.

[9] R. Kaul, Microwave engineering, vol. 8, no. 2. John Wiley \& Sons, 1989.

[10] A. B. Amado-Rey, Y. Campos-Roca, C. Friesicke, S. Wagner, and O. Ambacher, "GCPW GaAs Broadside Couplers at H-Band and Application to Balanced Power Amplifiers," IEEE Trans. Microw. Theory Tech., vol. 67, no. 1, pp. 78-85, 2019, doi: 10.1109/TMTT.2018.2873335.

[11] Z. J. Hou, Y. Yang, L. Chiu, X. Zhu, and Q. Xue, "Wideband Millimeter-Wave On-Chip Quadrature Coupler with Improved InBand Flatness in 0.13- $\mu \mathrm{m}$ SiGe Technology," IEEE Electron Device Lett., vol. 39, no. 5, pp. 652-655, 2018, doi: 10.1109/LED.2018.2814997.

[12] M. J. Chiang, H. S. Wu, and C. K. C. Tzuang, “Artificial-synthesized edge-coupled transmission lines for compact CMOS directional coupler designs," IEEE Trans. Microw. Theory Tech., vol. 57, no. 12, pp. 3410-3417, 2009, doi: 10.1109/TMTT.2009.2034305.

[13] I. Nasr, H. Knapp, K. Aufinger, R. Weigel, and D. Kissinger, "A 50$100-\mathrm{GHz}$ highly integrated octave-bandwidth transmitter and receiver chipset in 0.35- $\mu \mathrm{m}$ SiGe technology," IEEE Trans. Microw. Theory Tech., vol. 62, no. 9, pp. 2118-2131, 2014, doi: 10.1109/TMTT.2014.2337289.

[14] J. Lugo-Alvarez, A. Bautista, F. Podevin, and P. Ferrari, "Highdirectivity compact slow-wave CoPlanar waveguide couplers for millimeter-wave applications," in European Microwave Week 2014: Connecting the Future, EuMW 2014 - Conference Proceedings; EuMC 2014: 44th European Microwave Conference, 2014, pp. 1072-1075, doi: 10.1109/EuMC.2014.6986624.

[15] M. Margalef-Rovira et al., "Design of mm-Wave Slow-WaveCoupled Coplanar Waveguides," IEEE Trans. Microw. Theory Tech., vol. 68, no. 12, pp. 5014-5028, 2020, doi: 10.1109/TMTT.2020.3015974.

[16] A. L. Franc, E. Pistono, G. Meunier, D. Gloria, and P. Ferrari, "A lossy circuit model based on physical interpretation for integrated shielded slow-wave CMOS coplanar waveguide structures," IEEE Trans. Microw. Theory Tech., vol. 61, no. 2, pp. 754-763, 2013, doi: 10.1109/TMTT.2012.2231430.

[17] A. Bautista, A. L. Franc, and P. Ferrari, "Accurate Parametric Electrical Model for Slow-Wave CPW and Application to Circuits Design," IEEE Trans. Microw. Theory Tech., vol. 63, no. 12, pp. 4225-4235, 2015, doi: 10.1109/TMTT.2015.2495242.

[18] A. Davidson, K. Jones, and E. Strid, "LRM and LRRM calibrations with automatic determination of load inductance," in 36th ARFTG Conference Digest - Fall 1990, 1990, vol. 18, pp. 57-63, doi: 
10.1109/ARFTG.1990.323996.

[19] M. Wojnowski, V. Issakov, G. Sommer, and R. Weigel, "Multimode TRL calibration technique for characterization of differential devices," IEEE Trans. Microw. Theory Tech., vol. 60, no. 7, pp. 2220-2247, 2012, doi: 10.1109/TMTT.2012.2193136.

[20] G. F. Engen and C. A. Hoer, "Thru-Reflect-Line: An Improved Technique for Calibrating the Dual Six-Port Automatic Network Analyzer," IEEE Trans. Microw. Theory Tech., vol. 27, no. 12, pp. 987-993, 1979, doi: 10.1109/TMTT.1979.1129778.

[21] M. Uzunkol and G. M. Rebeiz, "140-220 GHz SPST and SPDT switches in $45 \mathrm{~nm}$ CMOS SOI," IEEE Microw. Wirel. Components Lett., vol. 22, no. 8, pp. 412-414, 2012, doi: 10.1109/LMWC.2012.2206017.

[22] F. Meng, K. Ma, K. S. Yeo, C. C. Boon, W. M. Lim, and S. Xu, "A 220-285 GHz SPDT Switch in 65-nm CMOS Using Switchable Resonator Concept," IEEE Trans. Terahertz Sci. Technol., vol. 5, no. 4, pp. 649-651, 2015, doi: 10.1109/TTHZ.2015.2436216.

[23] W. T. Khan et al., "A D-band (110 to $170 \mathrm{GHz}$ ) SPDT switch in 32 nm CMOS SOI," in 2015 IEEE MTT-S International Microwave Symposium, IMS 2015, 2015, pp. 1-3, doi: 10.1109/MWSYM.2015.7167061.

[24] F. Meng, K. Ma, and K. S. Yeo, "A 130-to- $180 \mathrm{GHz} 0.0035 \mathrm{~mm} 2$ SPDT switch with $3.3 \mathrm{~dB}$ loss and $23.7 \mathrm{~dB}$ isolation in $65 \mathrm{~nm}$ bulk CMOS," in Digest of Technical Papers - IEEE International SolidState Circuits Conference, 2015, vol. 58, pp. 34-35, doi: 10.1109/ISSCC.2015.7062852.

[25] T. Quémerais, L. Moquillon, J. M. Fournier, and P. Benech, "A SPDT switch in a standard $45 \mathrm{~nm}$ CMOS process for $94 \mathrm{GHz}$ Applications," in European Microwave Week 2010, EuMW2010: Connecting the World, Conference Proceedings - European Microwave Conference, EuMC 2010, 2010, pp. 425-428, doi: 10.23919/EUMC.2010.5614766.

[26] W. Aouimeur et al., "A Fully-Integrated High-Isolation Transfer Switch for G-band in-situ Reflectometer applications," 2020, doi: 10.1109/ICMIM48759.2020.9299098.

[27] H. Dogan, R. G. Meyer, and A. M. Niknejad, "Analysis and design of RF CMOS attenuators," IEEE J. Solid-State Circuits, vol. 43, no. 10, pp. 2269-2283, 2008, doi: 10.1109/JSSC.2008.2004325.

[28] J. Bae, J. Lee, and C. Nguyen, "A 10-67-GHz CMOS step attenuator with improved flatness and large attenuation range," in 2013 IEEE 13th Topical Meeting on Silicon Monolithic Integrated Circuits in RF Systems, SiRF 2013 - RWW 2013, 2013, pp. 78-80, doi: 10.1109/SiRF.2013.6489438.

[29] R. Kaunisto, P. Korpi, J. Kiraly, and K. Halonen, "A linear-control wide-band CMOS attenuator," in ISCAS 2001 - 2001 IEEE International Symposium on Circuits and Systems, Conference Proceedings, 2001, vol. 4, pp. 458-461, doi: 10.1109/ISCAS.2001.922272.

[30] B. H. Ku and S. Hong, "6-bit CMOS digital attenuators with low phase variations for x-band phased-array systems," IEEE Trans. Microw. Theory Tech., vol. 58, no. 7 PART 1, pp. 1651-1663, 2010, doi: 10.1109/TMTT.2010.2049691.

[31] Y. S. Dai, D. G. Fang, and Y. X. Guo, "A novel UWB (0.045-50 $\mathrm{GHz}$ ) digital/analog compatible MMIC variable attenuator with low insertion phase shift and large dynamic range," IEEE Microw. Wirel. Components Lett., vol. 17, no. 1, pp. 61-63, 2007, doi: 10.1109/LMWC.2006.887263.

[32] B. W. Min and G. M. Rebeiz, "A 1050-GHz CMOS distributed step attenuator with low loss and low phase imbalance," IEEE J. SolidState Circuits, vol. 42, no. 11, pp. 2547-2554, 2007, doi: 10.1109/JSSC.2007.907205.

[33] K. Park, S. Lee, and S. Jeon, "A New Compact CMOS Distributed Digital Attenuator," IEEE Trans. Microw. Theory Tech., vol. 68, no. 11, pp. 4631-4640, 2020, doi: 10.1109/TMTT.2020.3017820.

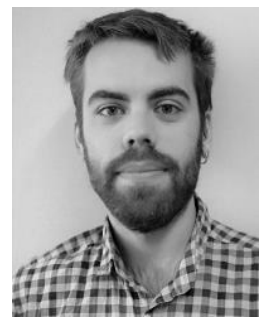

Marc Margalef-Rovira (M'16) received the engineering degree in electronics from the Rovira i Virgili University in 2016, his M.Sc. in wireless integrated circuits and systems from the Grenoble Alpes University in 2017. He received Ph.D. from that same university in 2020 as a part of
TIMA and RFIC-Lab laboratories. He is currently working as a postdoc in IEMN laboratory. His research interests include the design, characterization and test of mm-wave and sub- $\mathrm{THz}$ integrated circuits.

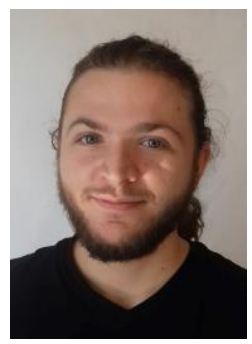

Olivier Occello received his M.Sc. degree in Wireless Integrated Circuits and Systems from Grenoble Alpes University. He is currently a Ph.D student in the TIMA and RFIC-Labs, in Grenoble. His research interests include the design and Built-In Self-Test of mm-Wave integrated circuits and the modeling of passive structures under the slow-wave effect.

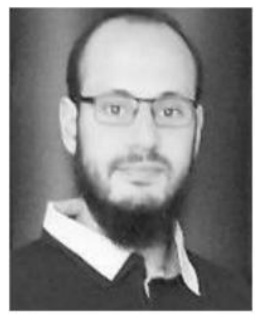

Abdelhalim A. Saadi (M'19) received the Engineer-ing degree in electronics and the Magister and the Ph.D. degrees in radiofrequency and microwave systems from the University of Science and Technology Houari Boumediene, Algiers, Algeria, in 2009, 2011, and 2016, respectively. He was with the Optical Transport Engineering Department in a large ICT company, for few years, where he was involved in many successful projects. In 2014, he joined the Centre de Développement des Technologies Avancées, Algeria, as a Research Associate, where he worked on the design of radio frequency and microwave filters in hybrid and integrated technologies, IC voltage-controlled oscillator (VCO) design, and the integration of mm-wave circuits in porous silicon technology. In 2018, he joined the TIMA Laboratory, Grenoble, France, as a PostDoctoral Researcher, and the RFIC-Lab, where he is involved in the design, the modeling, and the characterization of millimeter-wave (mm-wave) circuits integrated on advanced CMOS technologies. He is currently with NXP France.

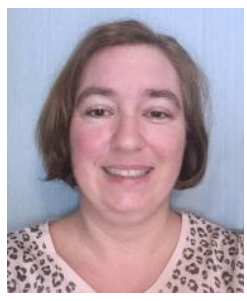

Vanessa Avramovic received her M.Sc. degree in telecommunications and networks from University of Savoie, France, in 2006. In 2007, she joined IMEP-LAHC laboratory as an RF engineer and subsequently joined IEMN in 2009. Currently, she works as an engineer in the RF, optical and photonic characterization platform. She is responsible of the low-power signal measurement up to 110 $\mathrm{GHz}, \mathrm{MEMs}$ and opto-RF characterization.

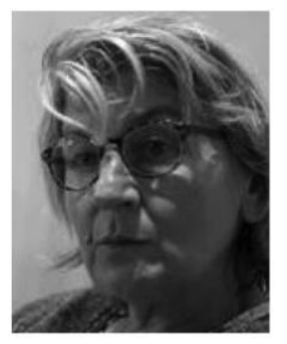

Sylvie Lepilliet Sylvie Lepilliet was born in Béthune, France, in 1964. She received the B.E. degree in electronics from the Centre National des Arts et Métiers (CNAM), Lille, France, in 1991.,In 1986, she joined the Centre Hyperfréquences et Semiconductors, University Lille, Lille. She is currently in charge of the highfrequency measurement facilities with the Institute of Electronics, Microelectronics and Nanotechnology, University Lille I, Villeneuve d'Ascq, France, particularly of the noise test set. 


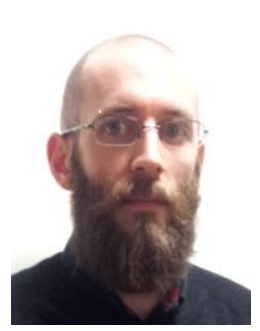

Loic Vincent received his $\mathrm{Ph}$. D. in electrotechnical and electronic engineering from Grenoble Institute of Technology (Grenoble INP, France) in 2010 . From 2007 to 2015 he was with the CIME Nanotech, France as an engineer in microsystems and sensors. Since 2015 he mainly focuses on microwave and millimeter-wave instrumentation.

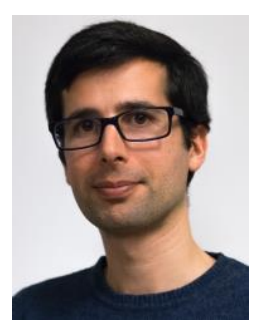

Manuel J. Barragan Manuel J. Barragan (M'14) received a M.Sc. degree in Physics in 2003 and a PhD in Microelectronics in 2009 , both from the University of Seville, Spain. He is currently a researcher with the French National Research Center (CNRS) at TIMA Laboratory, Grenoble, France. His research is focused on the topics of test and design for testability of analog, mixed-signal, and RF systems. He currently serves in the Technical Program Committee of the Design, Automation, and Test in Europe (DATE) Conference, IEEE European Test Symposium, and IEEE VLSI Test Symposium. His PhD research won a Silver Leaf Award at the IEEE PRIME conference in 2009 and, in 2011, his work was selected for inclusion in the 20th Anniversary Compendium of Most Influential Papers from the IEEE Asian Test Symposium. He received the Best Special Session Award in the 2015 IEEE VLSI Test Symposium and the Best Paper Award in the 2018 European Test Symposium.

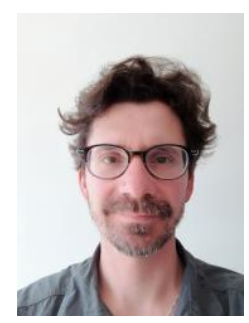

Emmanuel Pistono received the Ph.D. degree from Grenoble INP, Grenoble, France, in 2006. In 2007, he joined Université Joseph Fourier, Grenoble (now University Grenoble Alpes) and IMEPLAHC laboratory as an Assistant Professor. Since 2018, he is member of the RFIC-Lab (Université Grenoble Alpes) as an Associate Professor. His research interests include miniaturized and highperformance $\mathrm{RF} / \mathrm{millimeter-wave} \mathrm{passive} \mathrm{circuits} \mathrm{in} \mathrm{different}$ technologies, such as PCB, CMOS, and alternative technologies.

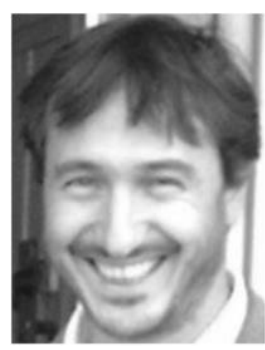

Sylvain Bourdel (M'05) received the $\mathrm{Ph} . \mathrm{D}$. degree in microelectronics from the National Institute of Applied Science (INSA), Toulouse, in 2000. He was with the LAAS Laboratory, Toulouse, where he was involved in radiofrequency systems modeling. He was particularly focused on spread spectrum techniques applied to 2.45-GHz transceivers. In 2002, he joined IM2NP, Marseille, where he headed along with Prof. H. Barthélemy the Integrated Circuit Design Team. He was involved in several projects dealing with UWB and RFID. In 2013, he joined the IMEP-LAHC Laboratory, Grenoble-INP, as a Full Professor. He currently leads the RFIC-Lab Laboratory. He works on radio-frequency and MMW IC design and integration. He particularly focuses on low-cost and low-power applications. He has authored or coauthored more than 80 referenced IEEE publications. His area of interest also includes system-level specifications, UWB and RFID.

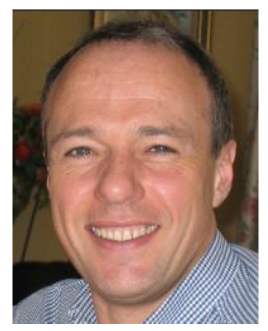

Christophe Gaquière was born in France, in 1966. He received the Ph.D. degree in electronic from the University of Lille in 1995. He is currently professor at the University of Lille and carries out his research activity at the Institut d'Electronique de Microélectronique et de Nanotechnology (IEMN).

The topics concern design, fabrication and characterization of HEMT's devices. He works on GaAs, InP, metamorphic HEMT's and now he is involved in the GaN and BiCMOS technologies. His main activities are microwave characterizations and design of components and circuits from applications going from $\mathrm{GHz}$ till $500 \mathrm{GHz}$. Christophe Gaquière is the author or co-author of more than 50 publications and 120 publications. He is the co-founder of MC2 technologies. He was responsible for the microwave characterization part of the common laboratory between Thales TRT and IEMN focus on wide band gap semiconductor ( $\mathrm{GaN}, \mathrm{SiC}$, and Diamond). At the present time he has in charge the Silicon millimeter wave advanced technologies part of the common lab between ST microelectronics and IEMN.

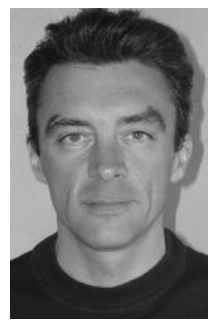

Philippe Ferrari received the $\mathrm{Ph}$. D. degree from the "Institut National Polytechnique de Grenoble" (INPG), France, in 1992, with honors. Since 2004, he is a professor at the University Grenoble Alpes, Grenoble, France. His main research interest concerns tunable and miniaturized devices, such as filters, phase shifters, matching networks, couplers, power dividers and VCOs. These devices are developed in many technologies, PCB, CMOS/BiCMOS, and nanowires, at RF and $m m$-wave frequencies. He has worked towards the development of slow-wave CPW, and developed new topologies of slowwave transmission lines, based on microstrip lines and SIWs, respectively. He is author or co-author of more than 230 papers published in international journals or conferences, and coholder of six patents. He is an IEEE senior member, a member of the Editorial Board of the International Journal on RF and Microwave Computer-Aided Engineering (Wiley), an Associate Editor of the International Journal of Microwave and Wireless Technologies (EuMA) and member of the Editorial Board of Electronics Letters. 